FERNANDO HAYASHI

AVALIAÇÃO IMUNO-HISTOQUÍMICA DE DEFEITOS DE FURCA CLASSE II TRATADOS PELO RETALHO DESLOCADO CORONARIAMENTE, ASSOCIADO OU NÃO À REGENERAÇÃO TECIDUAL GUIADA E ENXERTO DE TECIDO REPARATIVO DE ALVÉOLOS 


\title{
Fernando Hayashi
}

\author{
Avaliação imuno-histoquímica de defeitos de furca classe II \\ tratados pelo retalho deslocado coronariamente, associado ou não \\ à regeneração tecidual guiada e enxerto de tecido reparativo de \\ alvéolos
}

Tese apresentada à Faculdade de Odontologia da Universidade de São Paulo, para obter o Título de Doutor, pelo Programa de Pós-Graduação em Ciências Odontologicas.

Área de concentração: Periodontia

Orientador: Prof. Dr. Francisco Emílio Pustiglioni

São Paulo 
Hayashi, Fernando

Avaliação imuno-histoquímica de defeitos de furca classe II tratados pelo retalho deslocado coronariamente, associado ou não à regeneração tecidual guiada e enxerto de tecido reparativo de alvéolos / Fernando Hayashi; orientador Francisco Emílio Pustiglioni. -- São Paulo, 2009.

68p. : fig., tab.,; $30 \mathrm{~cm}$.

Tese (Doutorado - Programa de Pós-Graduação em Ciências Odontológicas. Área de Concentração: Periodontia) -- Faculdade de Odontologia da Universidade de São Paulo.

1. Defeitos de furca Classe II - Reparação periodontal

Periodontia

CDD 617.632

BLACK D64

AUTORIZO A REPRODUÇÃO E DIVULGAÇÃO TOTAL OU PARCIAL DESTE TRABALHO, POR QUALQUER MEIO CONVENCIONAL OU ELETRÔNICO, PARA FINS DE ESTUDO E PESQUISA, DESDE QUE CITADA A FONTE E COMUNICADA AO AUTOR A REFERÊNCIA DA CITAÇÃO.

São Paulo,

Assinatura:

E-mail: 
Hayashi F. Avaliação imuno-histoquímica de defeitos de furca classe II tratados pelo retalho deslocado coronariamente, associado ou não à regeneração tecidual guiada e enxerto de tecido reparativo de alvéolos [Tese de Doutorado]. São Paulo: Faculdade de Odontologia da USP; 2009.

São Paulo, ___ /2009

\section{Banca Examinadora}

1) $\operatorname{Prof}(a) . \operatorname{Dr}(a)$.

Titulação:

Julgamento:

Assinatura:

2) $\operatorname{Prof}(a) . \operatorname{Dr}(a)$.

Titulação:

Julgamento:

Assinatura:

3) $\operatorname{Prof}(a)$. $\operatorname{Dr}(a)$.

Titulação:

Julgamento:

Assinatura:

4) $\operatorname{Prof}(a)$. $\operatorname{Dr}(a)$.

Titulação:

Julgamento:

Assinatura:

5) $\operatorname{Prof}(a) . \operatorname{Dr}(a)$.

Titulação:

Julgamento:

Assinatura: 


\section{DEDICATÓRIA}

A Deus por tudo.

Aos meus Pais, Juliana e Chicão.

Aos meus alunos, pacientes e colegas de trabalho 


\section{AGRADECIMENTOS}

À FAPESP pelo auxílio à pesquisa 02/09757-2.

A W. L. Gore \& Associates, pelo fornecimento das membranas absorvíveis e à Carla Daley da W. L. \& Associates pela atenção dedicada a nossa pesquisa.

À Professora Doutora Karen Renata Nakamura Hikari pela ajuda, treinamento e paciência.

Aos meus parceiros nos experimentos, Fernando Peixoto Soares e Christiane Watanabe Yorioka.

À técnica Elisa da Disciplina de Patologia Bucal.

À Professora Titular da Disciplina de Patologia Bucal da FOUSP, Suzana Orsini Machado de Sousa, pela disponibilização do laboratório de patologia e imunohistoquímica.

Ao Professor Associado da Disciplina de Periodontia, Luiz A. P. A. de Lima da FOUSP, pela amizade e treinamento na digitalização dos cortes histológicos. 
Hayashi F. Avaliação imuno-histoquímica de defeitos de furca classe II tratados pelo retalho deslocado coronariamente, associado ou não à regeneração tecidual guiada e enxerto de tecido reparativo de alvéolos [Tese de Doutorado]. São Paulo: Faculdade de Odontologia da USP; 2009.

\section{RESUMO}

O objetivo desta pesquisa foi avaliar a reparação de defeitos de furca classe II em cães tratados com o retalho deslocado coronariamente, sozinho ou em associação com a regeneração tecidual guiada e o enxerto de tecido reparativo de alvéolos utilizando uma análise imuno-histoquímica. Os defeitos foram criados nos $2^{\text {os }}, 3^{\text {os }} \mathrm{e}$ $4^{\text {os }}$ pré-molares direitos e esquerdos mandibulares em quatro cães sem raça definida. No lado teste de cada cão, após a instrumentação radicular, os defeitos foram enxertados com o tecido reparativo, removidos de locais de extração dental com cinco dias de reparação. As áreas cirúrgicas foram recobertas com membranas absorvíveis e o retalho deslocado coronariamente suturado. No lado controle, após a instrumentação radicular, o retalho também foi deslocado coronariamente e suturado. Após 45 dias os cães foram sacrificados. As análises imuno-histoquímicas para osteonectina, osteopontina e sialoproteína óssea foram feitas no plano vestíbulo-lingual das furcas dos $3^{\text {os }}$ pré-molares. As marcações imuno-histoquímicas foram similares entre os grupos demonstrando que eles provavelmente estavam em um estágio reparativo semelhante.

Palavras-Chave: Defeitos de furca - Reparação periodontal - Periodontia 
Hayashi F. Immunohistochemical evaluation of class II furcation defects treated by coronally positionated flap associated or not with guided tissue regeneration and alveolar socket reparative tissue graft [Tese de Doutorado]. São Paulo: Faculdade de Odontologia da USP; 2009.

\section{ABSTRACT}

The aim of this research was to evaluate the repair of class II furcation defects in dogs treated with the coronally positioned flap alone or in association with guided tissue regeneration and post extraction tissue graft using an immunohistochemical analysis. The defects were created on the lower jaw right and left $2^{\text {nd }}, 3^{\text {rd }}$ and $4^{\text {th }}$ premolars on four mongrel dogs. On the test side of each dog, after root instrumentation, the defects were grafted with a alveolar socket reparative tissue removed from five days healing teeth extraction sites. The surgical areas were covered with absorbable membranes and a coronally positionated flap was sutured. At the control side, after root instrumentation the coronally positionated flap was sutured. After 45 days, the dogs were sacrificed. The immunohistochemical analyses for osteonectin, osteopontin and bone sialoprotein were done on the bucal-lingual plane extent of the $3^{\text {rd }}$ premolars furcations. The immunohistochemical expressions were similar among the two groups showing that they probably were in a similar healing stage.

Key-words: Furcation defects - Periodontal repair - Periodontics 


\section{LISTA DE FIGURAS}

Figura 4.1 - Defeitos de furca classe II criados preenchidos com enxerto

Figura 4.2 - Membranas posicionadas e estabilizadas

Figura 5.1 - Imuno-histoquímica para BSP (cão A - lado teste) demonstrando marcação no novo osso (NO), novo cemento (NC), tecido conjuntivo (TC) e ligamento periodontal pré-existente (LP) $(2,5 \mathrm{X})$

Figura 5.2 - Imuno-histoquímica para ONC (cão B - lado teste) demonstrando marcação negativa para o tecido conjuntivo (TC) e marcação moderada no tecido ósseo neoformado (NO) $(10 \mathrm{X})$

Figura 5.3 - Imuno-histoquímica para ONC (cão B - lado controle) demonstrando marcação moderada no tecido ósseo neoformado (NO) (10X)

Figura 5.4 - Imuno-histoquímica para ONC (cão A - lado teste) demonstrando marcação do novo cemento (NC) e cementoblastos (CB) (40X)

Figura 5.5 - Imuno-histoquímica para ONC (cão D - lingual) notar os canais harvesianos (HV) e linhas de cemento (LC) circundando-os (10X) ....42

Figura 5.6 - Imuno-histoquímica para ONC (cão D - lado teste) com o novo osso (NO) marcado em coloração mais forte $(2,5 \mathrm{X})$

Figura 5.7 - Imuno-histoquímica para ONC (cão D - lado controle) onde o osteoclasto (OC) não foi marcado (10 X) 
Figura 5.8 - Imuno-histoquímica para OPN (cão A - lado controle) demonstrando marcação para o osso pré-existente $(\mathrm{O})$ e tecido conjuntivo $(\mathrm{TC})$ tecido notar os canais (10X)

Figura 5.9 - Imuno-histoquímica para OPN (cão D - lado controle) demonstrando uma linha de marcação (seta) sobre a superfície do novo osso (NO) $(10 X)$

Figura 5.10 - Imuno-histoquímica para OPN (cão A - lado controle) demonstrando linhas mais marcadas sobre o novo cemento (NC) (seta maior) e entre a dentina e o novo cemento (seta menor) (40X). 43

Figura 5.11 - Imuno-histoquímica para BSP (cão A - lado teste) demonstrando marcação no novo osso (NO) com células que recobrem sua superfície e em seu interior também marcadas (40X).

Figura 5.12 - Imuno-histoquímica para BSP (cão A - lingual) demonstrando marcação do osso pré-existente $(0)$ menos evidente comparada à marcação do novo osso na Figura 5.11 (10 X) 45

Figura 5.13 - Imuno-histoquímica para BSP (cão A - lado controle) demonstrando marcação mais acentuada formando uma linha superficial (LS) sobre o novo cemento (NC) e ausência de marcação da dentina (D) (10X) ... 45 


\section{LISTA DE TABELAS}

Tabela 4.1 - Clone, título de tempo de incubação dos anticorpos primários 35

Tabela 5.1 - Resultados representativos da marcação por imuno-histoquímica para ONC

Tabela 5.2 - Resultados representativos da marcação por imuno-histoquímica para OPN

Tabela 5.3 - Resultados representativos da marcação por imuno-histoquímica para BSP 


\section{LISTA DE ABREVIATURA E SIGLAS}

$\begin{array}{ll}\text { RTG } & \text { regeneração tecidual guiada } \\ \text { PTFEe } & \text { politetrafluoretileno expandido } \\ \text { DFDBA } & \text { osso alógeno desmineralizado congelado liofilizado } \\ \text { IGF } & \text { fator de crescimento semelhante à insulina } \\ \text { PDGF } & \text { fator de crescimento derivado de plaquetas } \\ \text { RDC } & \text { retalho delocado coronariamente } \\ \text { ONC } & \text { osteonectina } \\ \text { OPN } & \text { osteopontina } \\ \text { BSP } & \text { sialoproteína óssea } \\ \text { PMEs } & \text { proteínas da matriz extracelular }\end{array}$




\section{SUMÁRIO}

p.

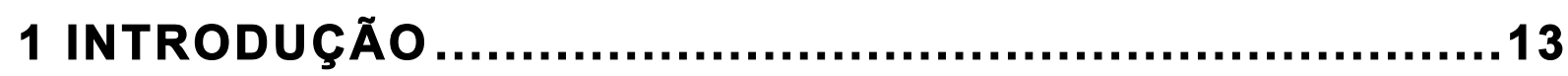

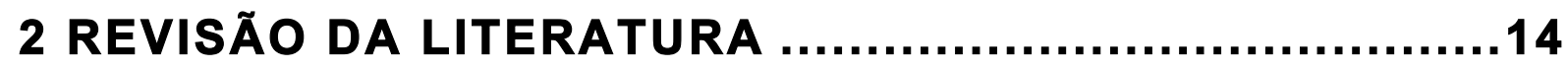

2.1 Análise Imuno-histoquímica dos tecidos periodontais utilizando marcado-

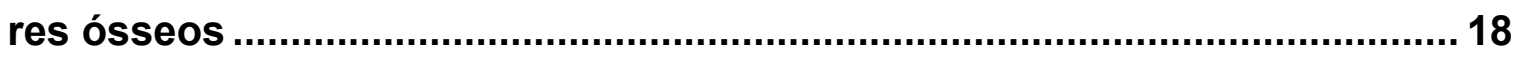

2.1.1 Marcadores ósseos em periodontia ..................................................18

2.1.1.1 Sialoproteína óssea...................................................................19

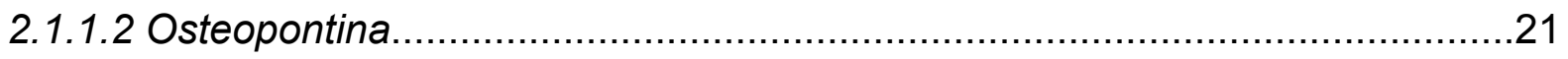

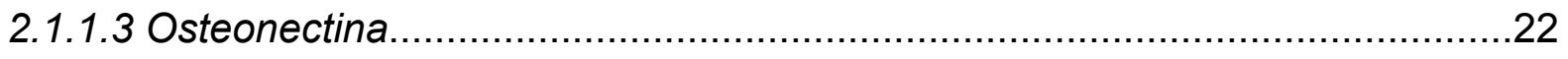

2.1.2 Estudos de reparação em periodontia que utilizaram os marcadores ósseos

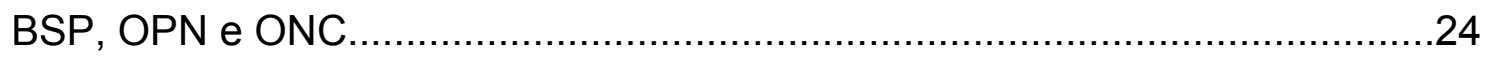

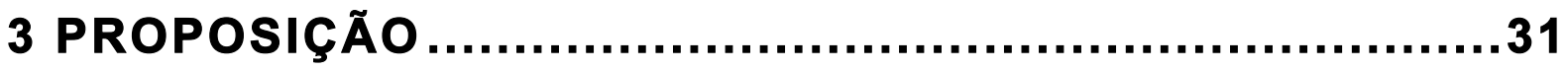

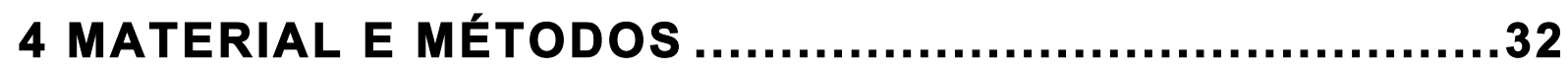

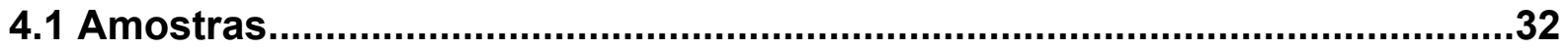

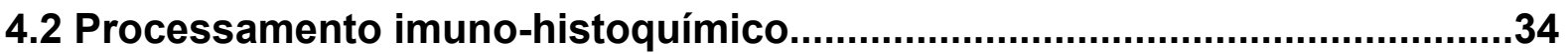

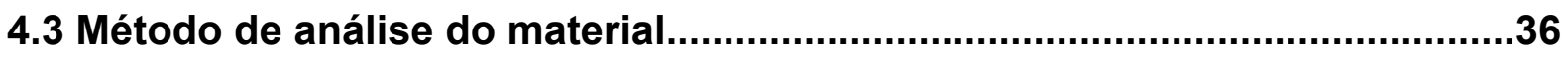

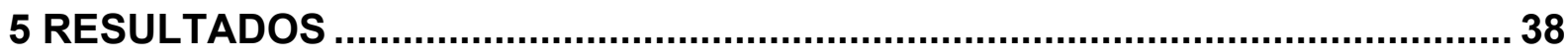

5.1 Descrição Geral dos Eventos Observados nas Lâminas.............................38

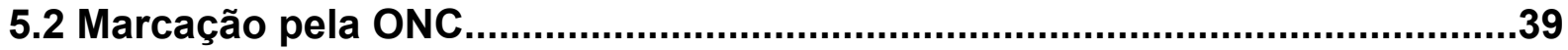

5.3 Marcação pela OPN.................................................................................... 40

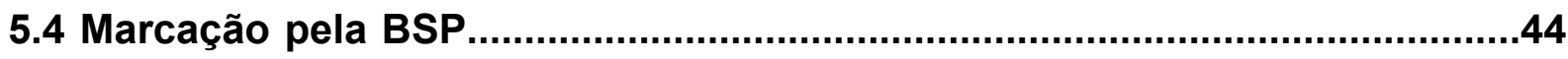


6 DISCUSSÃO

7 CONCLUSÃO

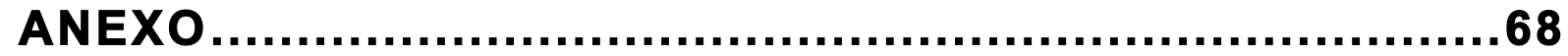




\section{INTRODUÇÃO}

Há anos técnicas cirúrgicas são estudadas com o intuito de se regenerar o periodonto destruído pela doença periodontal. Entre estas técnicas pode-se citar o enxerto de materiais com propriedades osteoindutivas, a regeneração tecidual guiada (RTG) e o retalho deslocado coronariamente (RDC) (GARRETT, 1994).

Alguns autores procuraram verificar se existem efeitos aditivos quando se associam diferentes técnicas regenerativas (CAFFESSE et al. 1993; GANTES et al. 1988; HAYASHI, 2004; LEKOVIC et al., 1990).

Estudos que utilizaram a reação de imuno-histoquímica tentaram elucidar a reparação das feridas periodontais a partir de proteínas da matriz extracelular, entre as quais estão as proteínas não colágenas, relacionadas à formação dos tecidos mineralizados, como a osteonectina, osteopontina e sialoproteína óssea. Seria interessante avaliar, por meio da técnica imuno-histoquímica, a evidenciação destas proteínas durante o processo de reparação das feridas quando se procura estimular a regeneração dos defeitos periodontais de diferentes maneiras. 


\section{REVISÃO DA LITERATURA}

A obtenção da regeneração dos tecidos destruídos pela doença periodontal tem sido objeto de estudo há varios anos. Em estudos clínicos após elevação de retalho e desbridamento, os autores relatavam terem conseguido regeneração periodontal principalmente em defeitos ósseos de três paredes (GOLDMAN; COHEN, 1958; PRICHARD, 1957). Mais tarde, estudos histológicos, tanto em animais quanto em seres humanos, demonstraram que tais procedimentos não eram previsíveis e, na verdade ao invés de ocorrer regeneração do aparato periodontal, com novo osso, ligamento periodontal e cemento, ocorria o preenchimento ósseo do defeito e a formação de um epitélio juncional longo (CATON; NYMAN; ZANDER, 1980; LISTGARTEN; ROSENBERG, 1979).

Diferentes técnicas tem sido propostas com o intuito de se tentar regenerar o aparato periodontal, entre elas a RTG (CAFFESSE et al., 1988; GOTTLOW et al., 1984; NYMAN et al., 1982), o RDC (CRIGGER et al., 1978; KLINGE; NILVÉUS; EGELBERG, 1985) e o enxerto de tecido ósseo neoformado (PASSANEZI et al, 1989). Embora as técnicas citadas tenham demonstrado resultados interessantes de regeneração, não apresentaram resultados previsíveis, nem propiciaram a regeneração total do defeito periodontal. É motivo de especulação se a associação de técnicas poderia melhorar os resultados de regeneração dos defeitos periodontais ou resultar em maior previsibilidade

Gantes et al. (1988) estudaram o RDC em humanos, sendo utilizadas furcas classe II. Trataram 14 defeitos com a utilização do RDC, associado à aplicação de ácido cítrico e, outros 16 defeitos, com a mesma técnica, mas com a adição de 
enxertos de DFDBA (Demineralized Freezed Dried Bone Allograft - Enxerto Alógeno de Osso Humano Congelado Desmineralizado e Desidratado). Após 12 meses, ambos os tratamentos atingiram ganhos de profundidade clínica de sondagem, nível clínico de inserção e nível ósseo, sendo este último medido por cirurgia de reentrada. Os resultados, para ambos os grupos, foram semelhantes, sendo que em $43 \%$ dos defeitos tratados com o RDC associado ao ácido cítrico ocorreu preenchimento ósseo total dos defeitos. O mesmo ocorreu em $44 \%$ dos defeitos tratados com a adição do enxerto ósseo.

Lekovic et al. (1990) realizaram estudo em 15 pacientes tendo, cada um, dois molares inferiores com envolvimento de furca grau II. Em um dos molares utilizaram uma membrana não absorvível associada ao enxerto de hidroxiapatita porosa e, no outro molar, apenas a membrana. O RDC foi realizado para ambos os dentes. Aos seis meses, ambos os procedimentos resultaram em ganhos de inserção clínica e redução de profundidade clínica de sondagem, não havendo diferenças estatísticas entre os resultados. Quanto ao preenchimento ósseo, medido por cirurgia de reentrada, a implementação com hidroxiapatita se mostrou mais eficiente.

Caffesse et al. (1993) testaram a combinação da RTG com a utilização de enxerto ósseo. Quatro cães com doença periodontal natural foram utilizados neste estudo. Os dentes tratados foram os segundos, terceiros e quartos pré-molares e primeiros molares inferiores. Em um hemiarco foi colocado o DFDBA nas furcas e, sobre estas, as membranas de PTFEe (Politetrafluoroetileno Expandido). No lado contralateral foram colocadas apenas as membranas sobre os defeitos de furca. Após seis semanas, as membranas foram removidas e após completados quatro meses, os cães foram sacrificados. Os cortes histológicos foram realizados no 
sentido mésio-distal e vestíbulo-lingual. Ambos os tratamentos resultaram em formação de novo osso, cemento e inserção conjuntiva. Não houve diferenças estatisticamente significantes entre o grupo tratado com a RTG combinada ao enxerto ósseo e o grupo tratado apenas com a RTG.

Bogle et al. (1997) estudaram, em seis cães com doença periodontal, a utilização de membranas à base de ácido poliláctico sobre defeitos de furca classe II. Foram utilizados dezesseis pré-molares, os quais, após afastados os retalhos, tiveram as raízes instrumentadas e os defeitos desbridados. Em oito dentes foram colocadas membranas absorvíveis antes da sutura do retalho. Os retalhos, segundo os autores, foram levemente deslocados corionariamente. Seis meses após a cirurgia reconstrutiva os cães foram sacrificados para análise histológica. Os cortes foram realizados no sentido vestíbulo-lingual. Os autores relataram que $71 \%$ dos sítios tratados com membranas demonstraram completa regeneração, formando novo cemento, osso e ligamento periodontal enquanto que isto ocorreu em apenas $14 \%$ dos sítios sem as membranas.

Andersson et al. (1994) trataram furcas classe II em oito pacientes nos quais, em nove furcas, foram utilizadas membranas não absorvíveis associadas ao retalho reposto e, em nove, o RDC associado a aplicação de ácido cítrico. Neste estudo ocorreram melhorias nos parâmetros clínicos para ambos os grupos, entretanto, os autores não encontraram diferenças siginificantes entre o grupo tratado com RTG e o tratado com deslocamento coronário.

Yorioka (2004) realizou estudo em quatro cães nos quais, foram criados nos segundos, terceiros e quarto pré-molares inferiores, defeitos de furca classe II. Estes defeitos foram tratados por enxerto de tecido reparativo de alvéolos de extração com 5 dias de reparação no lado teste. Em ambos os lados foram realizados o RDC. 
Após 45 dias de reparação, os defeitos foram avaliados com cortes no sentido vestíbulo-lingual e, histometricamente, foram medidas horizontalmente os seguintes parâmetros: novo osso, novo cemento, tecido conjuntivo e migração apical do epitélio juncional. O estudo demonstrou formação de novo cemento, novo osso, formação de tecido conjuntivo inserido ou aderido e migração apical do epitélio juncional tanto no grupo teste quanto no grupo controle de maneira similar não havendo diferenças estatisticamente significantes entre os grupos.

Hayashi (2004) realizou estudo semelhante ao de Yorioka (2004) sendo que, sobre os enxertos foram colocadas membranas absorvíveis à base de ácidos poliglicólico e poliláctico . Neste estudo também houve nova formação de cemento, osso e tecido conjuntivo inserido ou aderido e migração apical de epitélio juncional nos lados teste e controle. Não houve diferenças estatisticamente significantes entre os grupos.

Soares et al. (2005) também utilizaram metodologia semelhante a de Yorioka (2004), com a diferença que, os tecidos reparativos eram provenientes de alvéolos nos quais, foram injetados fatores de crescimento imediatamente após as extrações. Os fatores de crescimento utilizados foram o PDGF (Platelet Derived Growth Factor - Fator de crescimento Derivado de Plaquetas) e o IGF (Insulin-like Growth Factor Factor de Crescimento Semelhante à Insulina). Novamente, nos lados teste e controle, foram encontrados novo osso, novo cemento, tecido conjuntivo inserido ou aderido e migração apical do epitélio juncional. Não foram observadas diferenças estatisticamente significantes entre os grupos. 


\subsection{Análise Imuno-histoquímica dos tecidos periodontais utilizando marcadores ósseos}

\subsubsection{Marcadores ósseos em periodontia}

A matriz óssea é constituída de porção mineral formada por hidroxiapatia (67\%) e porção orgânica a base de colágeno (27 \%) e proteínas não colágenas (5 \%) (NANCl; SOMERMAN, 2003). As proteínas não colágenas vem sendo estudadas para que se entenda o papel que desempenham na formação, mineralização e reabsorção óssea bem como o seu papel na constituição do cemento (NANCl; SOMERMAN, 2003; ROACH, 1994).

A despeito das diferenças morfológicas do osso e do cemento, seus constituintes se assemelham. O cemento possui cerca de $45 \%$ a $50 \%$ de hidroxiapatita e o restante de proteínas colágenas e não colágenas, sendo mais de 90\% de origem colágena (NANCl; SOMMERMAN, 2003).

As proteínas não colágenas, presentes nas células e matriz extracelular, podem ser identificadas através de um procedimento laboratorial, baseado em uma reação antígeno-anticorpo, a Imuno-histoquímica. Entre as proteínas ósseas encontradas no osso e no cemento estão a Sialoproteína Óssea (BSP), a Osteonectina (ONC), a Osteocalcina (OC) e a Osteopontina (OPN). Estas proteínas são produzidas pelos osteoblastos (NANCl; SOMERMAN, 2003; ROACH, 1994), porém, elas não são apenas encontradas no osso, mas também em tipos celulares 
que não tem linhagem óssea. As funções destas proteínas não são totalmente compreendidas. (GANSS; KIM; SODEK, 1999).

Lao, Marino e Bartold (2006) avaliaram imuno-histoquimicamente o cemento de dentes acometidos por doença periodontal. Nas áreas de cemento expostas ao processo de doença não foram detectadas a OPN e a BSP. Nas áreas saudáveis, houve marcação no ligamento periodontal demonstrando a presença destas proteínas. Este fato pode levar a crer que a presença destas proteínas podem influenciar na regeneração dos tecidos da área.

Em estudo examinando a formação óssea da calvária de ratos em desenvolvimento fetal e após o nascimento, Cowles et al. (1998) notaram que a BSP tem marcação já em osteoblastos jovens e que a OPN, ONC e OC apresentam marcação máxima após o nascimento, denotando um papel mais evidente em um estágio mais avançado da formação óssea. A seguir, nos ítens 2.1.1.1, 2.1.1.2 e 2.1.1.3 são revisadas as proteínas não colágenas utilizadas no presente estudo.

\subsubsection{Sialoproteína óssea}

A BSP é natural de tecidos mineralizados sendo encontrada em altas concentrações no osso em regeneração. Isto faz ressaltar o interesse por esta proteína como um potencial nucleador de hidroxiapatita e como um marcador específico de diferenciação de osteoblastos e cementoblastos. A BSP constitui aproximadamente $10 \%$ das proteínas não colágenas do osso ou cemento. Na dentina esta concentração cai 10 vezes. Além da função de nucleação de 
hidroxiapatita, outras funções da BSP são estudadas, embora não sendo ainda totalmente compreendidas. Entre estas funções estão a inibição do crescimento dos cristais de hidroxiapatita, um mecanismo alternativo de adesão celular, estímulo do aumento da atividade osteoclástica e, ainda, a sinalização mitogênica para préosteoblastos e diferenciação destes em osteoblastos estimulando a mineralização óssea (GANSS; KIM; SODEK, 1999).

A marcação pela BSP é altamente específica para tecidos mineralizados como osso, cemento, dentina, e esmalte sendo a marcação menor nestes dois últimos tecidos. Os únicos locais não mineralizados onde a BSP é encontrada são a placenta e plaquetas. A imuno-histoquímica demonstra marcação no osso cortical e trabecular, bem como no osteóide e ligamento periodontal normal, ou em reparação. A marcação nas linhas cementantes e de reversão indicam um potencial da BSP na adesão de células à superfícies mineralizadas. A marcação da BSP é fortemente associada ao mineral extrafibrilar que é mais abundante no osso imaturo. Conforme o osso amadurece e o mineral é formado entre as fibrilas de colágeno a marcação decresce. Um fator interessante é que apesar de presente no osteoclasto, a BSP parece não estimular o aumento do número destes, sendo que seu papel talvez seja importante na regulação da atividade destas células. A despeito das dúvidas que cercam a BSP, esta é um importante marcador para se estudar a diferenciação osteogênica e a mineralização óssea. (GANSS; KIM; SODEK, 1999) 


\subsubsection{Osteopontina}

A OPN foi inicialmente chamada de sialoproteína óssea I sendo que a BSP atual era chamada de sialoproteína óssea II. O nome osteopontina deve-se ao fato de que esta proteína faz uma ponte entre as células e a hidroxiapatita. Embora a linfocina que proporcionaria tal feito também tenha sido encontrada em linfócitos e macrófagos o nome osteopontina persistiu. Ela é encontrada no osso, cemento, dentina e ainda em diversos tipos de tecidos como o mamário, nervoso e pancreático, entre outros. Suas funções não estão elucidadas mas alguns fenômenos são atribuídos a ela. Por ser encontrada em locais do corpo onde não deve ocorrer precipitação de cálcio, como nos rins, por exemplo, e no osso parece inibir a nucleação e o crescimento dos cristais de hidroxiapatita, seu papel talvez seja de controle da mineralização. A OPN, em sítios com fraturas ou em mineralização parece recobrir suas superfícies, mediando a aderência de células para que possa ocorrer a reparação. Nos processos da neoformação e remodelação óssea, osteoblastos ainda pouco diferenciados migram para a superfície da matriz óssea ainda não mineralizada e depositam uma camada pobre em fibrilas de colágeno mas ricas em OPN. Após a deposição desta camada a hidroxiapatita é acumulada nesta região. Este processo ajuda a explicar as linhas de reversão. A OPN é particularmente prevalente no compartimento inter-fibrilar da matriz extracelular do osso imaturo. Primeiro ela aparece em pequenos focos de mineralização dentro do osteóide, com altos níveis sendo observados nos frontes de mineralização. Assim, por analogia, a OPN sendo depositada nos frontes de mineralização, atua, juntamente com outras proteínas não colágenas, como uma 
argamassa entre os blocos de colágeno. Ajudando na coesão da matriz e ainda nos eventos de mineralização. Como no osso lamelar as fibrilas de colágeno são empacotadas mais densamente, diminui a quantidade de proteínas não colágenas. Assim, a OPN deve ter um papel anterior à formação do osso lamelar, talvez pré-

definindo as propriedades biomecânicas do osso. É possível que a presença mais difusa da OPN na matriz óssea tenha alguma influência na atividade osteoclástica durante a reabsorção do osso imaturo, interferindo na sua substituição por osso lamelar. A OPN também está abundantemente presente no cemento, tanto no celular, quanto no acelular, em níveis maiores que no osso, particularmente no cemento acelular. Na união entre a dentina e cemento também existe um acúmulo adicional de OPN, talvez desempenhando um papel na integração entre as fibrilas de colágeno da matriz de cemento e as fibrilas da dentina. Na dentina a quantidade de OPN é menor e seu papel é mais incerto. Altos níveis de OPN são encontrados em osteoblastos e osteócitos (SODEK; GANSS; MCKEE, 2000).

\subsubsection{Osteonectina}

A ONC é uma proteína encontrada em diferentes tipos celulares e é associada ao desenvolvimento, remodelação, turnover celular e reparação. "In vitro" suas principais funções são a anti-proliferação e a contra-adesão. Também é chamada de SPARC (Secreted Protein, Acidic and Rich in Cysteine- Proteína Secretada Ácida e Rica em Cisteína) e é a maior proteína não colágena encontrada na matriz óssea. Faz parte de uma família de proteínas com quantidades 
aumentadas quando é necessário alguma mudança na forma e mobilidade celular. A ONC tem alta afinidade pelo cálcio tendo, aparentemente, sua função e estrutura modulada por este íon. Um efeito interessante é o fato da ONC parecer interagir com o PDGF (Platelet Derived Growth Factor - Fator de Crescimento Derivado de Plaquetas) AB e BB, o VEGF (Vascular Endothelial Growth Factor - Fator de Crescimento Vascular Endotelhial) e o bFGF(basic Fibroblastic Growth Factor Fator de Crescimento Fibroblástico básico). Esta interação evitaria que estes fatores de crescimento alcançassem os receptores de outras células, podendo regular os efeitos proliferativos destes fatores, tendo um papel provável na diferenciação celular. A contra-adesão talvez auxilie no fato de que esta proteína possa modificar a forma da célula, o que é temporariamente necessário para células em migração e proliferação (YAN; SAGE, 1999). O colágeno tipo I, que constitui aproximadamente $90 \%$ das proteínas do tecido ósseo, quando ligado a osteonectina forma um complexo que consegue se ligar aos cristais de apatita e íons de cálcio (TERMINE et al., 1981). Em um estudo avaliando a marcação da ONC em tecidos conjuntivos mineralizados associados aos dentes de porco, foi observado que a sua presença foi maior e mais uniforme na fase fetal que na fase adulta. Entretano, no cemento teve pouca marcação (TUNG et al., 1985). 
2.1.2 Estudos de reparação em periodontia que utilizaram os marcadores ósseos BSP, OPN e ONC

Amar et al. (1995) realizaram estudo no qual três pacientes com dentes condenados por doença periodontal avançada foram tratados com regeneração óssea guiada (membranas não absorvíveis de PTFEe). Após seis semanas, os dentes, juntamente com tecidos circunjacentes, foram analisados por imunohistoquímica para ONC, BSP e fosfatase alcalina. Os autores relataram a importância de um estudo que verificasse se os eventos celulares e moleculares da regeneração guiada seriam, ou não, similares aos da reparação ou daqueles que ocorrem durante a formação dos tecidos embrionários. A análise imuno-histoquímica revelou que para ONC houve uma marcação forte na matriz extracelular, principalmente em áreas nodulares. A densa rede de tecido conjuntivo também foi pigmentada. As biópsias de gengiva demonstraram uma distribuição fraca de ONC nos fibroblastos e algumas fibras da matriz extracelular. Para a BSP, o tecido ósseo desmineralizado e locais de tecido mole periodontal demonstraram marcação. Entretanto, nos tecidos gengivais esta marcação tendeu para o negativo. Para os autores a presença de marcação nos tecidos moles periodontais pode ter demonstrado um potencial de diferenciação em tecido duro. O tecido conjuntivo adjacente ao osso maduro foi semelhante, histologicamente e imunohistoquimicamente, aos tecidos moles colhidos de baixo das membranas, podendo ser um andaime para a formação de osso intramembranoso. Como a ONC foi encontrada em estudos anteriores em áreas de neoformação óssea, a presença desta em áreas nodulares poderia demonstrar que este evento pode preceder a 
regeneração periodontal. Quanto à BSP, para os autores, como estudos anteriores levaram a crer que seria um marcador acurado para a formação de cemento e osso, a presença desta nos aglomerados celulares pode sugerir uma formação futura de osso e cemento. Os autores concluíram que os tecidos moles neoformados, abaixo da membrana, contém células e macromoléculas da matriz extracelular normalmente encontradas no osso e cemento.

Amar et al. (1997) realizaram um estudo em incisivos superiores de seis macacos utilizando a RTG em defeitos periodontais induzidos. As membranas utilizadas foram as de PTFEe e as amostras foram analisadas 6 semanas após a cirurgia de RTG. A microscopia óptica demonstrou que o tecido mole sob a membrana exibia grande celularidade, com células de forma alongada, do tipo fibroblastos, em uma matriz extracelular densa. Células semelhantes a fibroblastos, porém arredondadas, foram encontradas formando agregados e a formação de novo osso foi evidente. Nos controles, onde foram realizados os defeitos com tratamento sem membrana, não houve evidência de nódulos ou neoformação de tecido duro. Os tecidos sob a membrana apresentaram marcação forte para a ONC na matriz extracelular densa, especialmente na área entre o tecido duro neoformado e as áreas nodulares. No grupo controle houve alguma marcação mas não tão evidente. Para a BSP foi encontrada marcação nas áreas de neoformação óssea sob a membrana, em áreas de tecido conjuntivo entre os fragmentos de novo tecido duro e a camada celular adjacente. As demais áreas foram negativas para a BSP. No controle não foi detectada a BSP. Também, foram analisados outros marcadores como as proteínas morfogenéticas ósseas 2, 4 e 7 e, ainda, a proteína de inserção de cemento. Para os autores ficou evidente o poder intrínseco das membranas em 
promover a neoformação de tecido duro (osso e cemento) tendo como comparação o grupo controle.

Ivanovski et al. (2000) realizaram estudo em quatro cães nos quais defeitos periodontais foram criados nos segundos pré-molares. Os defeitos foram tratados pela regeneração óssea guiada utilizando membranas de PTFEe. Os cães foram sacrificados após 4 semanas. A análise imuno-histoquímica foi realizada para as proteínas morfogenéticas ósseas 2 e 4, colágeno tipo I, III, decorin, biglican, OC, BSP e OPN. Os resultados foram analisados qualitativamente. A BSP e a OPN marcaram moderadamente a matriz extracelular do tecido conjuntivo que preenchia o defeito e fracamente as células neste tecido. Também, marcaram fortemente o cemento e a margem coronal da matriz extracelular do osso em regeneração. Nesta região a OPN estava localizada em uma linha fina que pareceu coincidir com o fronte de mineralização, enquanto que a BSP pareceu estar mais granular e difusa. Osteócitos e alguns osteoclastos e uma pequena porção de osteoblastos estavam intensamente marcados nas áreas de regeneração óssea. A marcação por OPN no lado não tratado (lingual) foi forte no cemento e na matriz óssea imediatamente adjacente ao ligamento periodontal. $\mathrm{O}$ cemento e grande parte da interface ligamento-osso exibiram fraca marcação para a BSP. Os autores enfatizaram a heterogeinidade celular dos tecidos periodontais em reparação em relação aos diversos marcadores utilizados no estudo. Quanto à presença da OPN e da BSP na margem coronal do osso em neoformação e no cemento neoformado, os autores ressaltaram a importância deste fato em um possível papel destas na regeneração periodontal. A forte marcação por OPN pode, para os autores, ressaltar sua importância como um marcador precoce da regeneração que é temporal e espacialmente relacionada às intensas proliferação e migração celular nas 
populações osteogênicas e do ligamento periodontal. A despeito da indicação de um efeito osteogênico e cementogênico os autores enfatizaram as dificuldades de se manipular os eventos celulares e moleculares para que se obtenha uma regeneração completa e previsível.

Kawagushi et al. (2001) realizaram estudo em ratos para tentar caracterizar a matriz extracelular depositada sobre a dentina, durante os estágios iniciais da regeneração periodontal. Os ratos foram sacrificados após 3 semanas. Neste estudo não foi utilizada a técnica da RTG mas apenas a raspagem associada ao retalho reposto. Analisando a ultra-estrutura da dentina e o material que a recobre durante a reparação, os autores detectaram a BSP e a OPN, indicando que o acúmulo destas pode ocorrer nas etapas iniciais de reparação. Porém, a distribuição delas não foi uniforme e a função destas na reparação não pôde ser explicada.

Sculean et al. (2002) realizaram estudo em três macacos nos quais foram criados defeitos intra-ósseos crônicos. Estes defeitos foram tratados por RTG, proteínas da matriz de esmalte, a combinação de ambas, ou retalho reposto. A membrana utilizada foi uma membrana de ácido poliláctico e poliglicólico (ResolutGore \& Associates) Após cinco meses o material foi avaliado imunohistoquimicamente para a OPN, colágeno tipo I e III. As partes intactas do periodonto serviram de controle. A OPN, embora tenha sido evidenciada em osso e tecidos novos e pré-existentes, pareceu ter marcação mais intensa nos bordos do novo osso e novo cemento. Este fato, neste período de cinco meses, pôde indicar, segundo os autores,que esta proteína tenha um importante papel na remodelação ou mineralização de tecidos duros. Entretanto, os autores ressaltaram que a OPN também foi detectada no ligamento periodontal, tecido conjuntivo gengival e epitélio. Uma explicação deste efeito contraditório foi o fato de os anticorpos utilizados serem 
policlonais, ou ainda, que a OPN já fora localizada inclusive em outros tipos teciduais não mineralizados e até mesmo em fluidos corporais como o sangue e até mesmo na urina. Apesar das modalidades diferentes de tratamento os autores não detectaram padrões diferentes de reparação em relação as proteínas na matriz extracelular.

Christgau et al. (2007) analisaram a marcação de proteínas da matriz extracelular em diferentes tempos de reparação no tratamento de defeitos de furca de vinte e um cães com doença periodontal avançada nos segundos, terceiros e quarto pré-molares inferiores utilizando a RTG comparada ao retalho reposto. Por meio de imuno-histoquímica foi avaliada a marcação de colágenos tipos I e III, a fibronectina, a BSP e a OPN. Os tempos de sacrifício foram duas, quatro e oito semanas, bem como três, seis e doze meses após as cirurgias. Nas furcas dos dentes superiores sem tratamento não foi observada a marcação de BSP nem de OPN no ligamento periodontal. A matriz do cemento foi positiva para a BSP e OPN. Os cementócitos foram positivos para a BSP mas não para a OPN. As interfaces entre o cemento e a dentina, bem como o cemento e o ligamento, tiveram forte marcação para a BSP. O osso interradicular teve uma fraca marcação para OPN e BSP. Os osteócitos foram marcados para a BSP. Os osteoclastos foram marcados apenas pela a OPN. A linha de reversão foi fortemente marcada pela BSP e OPN. Em geral, os locais com cemento e matriz óssea fortemente mineralizados demonstraram uma marcação muito fraca. Os autores atribuíram este fato à possibilidade de que os antígenos possam ter sido mascarados pelos minerais presentes na matriz. As áreas tratadas pela raspagem, associada ao retalho reposto, tiveram uma regeneração substancialmente menor que as áreas tratadas pela RTG, entretanto, os autores ressaltaram que o padrão espacial e temporal de marcação 
das proteínas da matriz extracelular foi similar para os diferentes grupos. Em duas semanas o defeito estava preenchido em sua maior parte por tecido de granulação altamente infiltrado e vascularizado sendo que a OPN e a BSP não foram encontrados nestes tecidos. A partir de então, houve um forte processo de remodelação que começou a ocorrer do osso periférico ao defeito. Vários osteoclastos marcados por OPN estavam ativos, demonstrando reabsorção superficial do osso pré-existente. A interface osteoclastos/osso estava fortemente marcada para OPN. A reabsorção foi seguida pela marcação nas superfícies no osso antigo e novo. O novo osso, entretanto, foi encontrado apenas em alguns espécimes nas duas primeiras semanas e a neoformação foi mais evidente a partir da quarta semana. As áreas marginais do osteóide e da matriz de tecido ósseo imaturo bem como as linhas de reversão tiveram uma forte marcação para a OPN. Interessante é que, mesmo após 6 meses o novo osso formado teve uma forte marcação para a OPN e a BSP. Quanto ao cemento, o padrão de marcação das proteínas da matriz extracelular foi semelhante ao do osso. Após duas semanas havia áreas das superfícies das raízes com odontoclastos reabsorvendo dentina e cemento residual. Os citoplasmas destas células, bem como as interfaces destas com a superfície dentária, demonstraram forte marcação para OPN. A interface entre a superfície dentária e o tecido conjuntivo neoformado foi marcada fortemente por BSP e OPN. Após este estágio houve uma forte condensação do tecido conjuntivo sobre a superfície dentária, formando um cementóide. Após quatro semanas houve a formação de uma fina camada de cemento sobre a raiz tratada. Esta camada teve sua espessura e sua extensão em direção à face vestibular aumentada ao longo dos doze meses subsequentes, entretanto, em oito semanas a maior parte do cemento que iria recobrir a superfície dentária já estava presente. A matriz do novo cemento 
apresentou marcação para a OPN e BSP e foi mais forte nas áreas marginais. A área de interface entre o novo cemento e a dentina também foi marcada para a OPN e a BSP. A interface entre o novo cemento e o tecido conjuntivo só foi corada pela BSP. Quanto ao ligamento periodontal, até a segunda semana, as fibras colágenas estavam basicamente paralelas à superfície do dente, a partir da quarta semana, quando o novo cemento começou a ser depositado, as fibras colágenas se inseriram no cemento e, o novo ligamento foi completado aos três meses. Não foram encontrados no ligamento periodontal a BSP nem a OPN. Os autores ressaltaram a influência da infecção sobre a marcação das proteínas da matriz extracelular e da regeneração do defeito. Como exemplo os autores demonstraram que a BSP estava presente em uma área sem infiltrado inflamatório e ausente quando este infiltrado estava presente envolvendo a membrana.

Assim baseados nos dados encontrados na literatura, seria interessante analisar, por meio de reações imuno-histoquímicas, o estágio evolutivo da reparação de defeitos periodontais tratados cirurgicamente. 


\section{PROPOSIÇÃO}

Este estudo teve como proposta avaliar e comparar o padrão de marcação imuno-histoquímica na reparação de defeitos de furca grau II, criados artificialmente em cães, quando tratados pela técnica do retalho deslocado coronariamente somente e este associado à técnica de regeneração tecidual guiada, utilizando uma membrana absorvível mais enxerto de tecido reparativo de alvéolos, com a finalidade de se obter informações a respeito da influência das diferentes técnicas sobre o estágio reparativo e constituição dos tecidos através das presenças da ONC, BSP e OPN. 


\section{MATERIAL E MÉTODOS}

\subsection{Amostras}

Neste estudo foram utilizadas peças emblocadas em parafina advindas de estudo anterior (HAYASHI, 2004) com aprovação pelo Comitê de Ética em Pesquisa (Anexo A). Foram escolhidos os terceiros pré-molares inferiores provenientes de quatro cães de porte médio, sem raça definida, nos quais foram criados defeitos de furca classe II tratados por RDC no lado controle, e RDC mais RTG associado ao uso de enxerto de tecido reparativo de alvéolo de dentes estraídos com cinco dias de reparação.

Serão descritos resumidamente, a metodologia de criação dos defeitos, realização do RDC, manejo pré e pós-operatório dos animais, os procedimentos laboratoriais para obtenção dos cortes no sentido vestíbulo-lingual das furcas e os emblocamentos das amostras em parafina. Maiores detalhes podem ser encontrados em trabalhos já publicados (HAYASHI, 2004; SOARES et al., 2005).

No dia demonominado -5 , os animais foram sedados e submetidos à anestesia geral. Após a elevação de um retalho de espessura total por vestibular, os segundos e terceiros pré-molares superiores foram extraídos. Retalhos deslocados coronariamente foram realizados e suturados para que os alvéolos fossem totalmente recobertos.

Cinco dias após as extrações, no dia denominado 0 (zero), os cães foram novamente sedados e anestesiados. Um retalho de espessura total com excisão de 
margem foi realizado envolvendo os segundos, terceiros e quarto pré-molares mandibulares. Foram criados defeitos ósseos de furca classe II com dimensões padronizadas: $5 \mathrm{~mm}$ de altura (medidos a partir do teto da furca), $5 \mathrm{~mm}$ de largura mesio-distal e $4 \mathrm{~mm}$ de profundidade no sentido vestíbulo-lingual.

As superfícies radiculares expostas foram meticulosamente raspadas e aplainadas com ultrasson e curetas, com a finalidade de se remover o cemento exposto. Marcas de referência foram realizadas nas superfícies radiculares, junto ao fundo do defeito e à junção cemento esmalte, para delimitar o defeito e servir como referências para a análise microscópica.

Posteriormente à criação dos defeitos, o tecido reparativo dos alvéolos foi coletado e inserido nos defeitos de um dos lados da mandíbula escolhidos aleatoriamente, sendo este o lado teste (Figura 4.1). Após a inserção do enxerto, o mesmo foi recoberto por uma membrana absorvível (Resolut $\mathrm{XT}^{\circledR}$ modelo XTW1 W.L. Gore \& Associates, Inc., Flagstaf, Arizona, Estados Unidos) (Figura 4.2) para RTG antes da sutura do RDC. No lado controle, após a criação do defeito, o RDC foi suturado

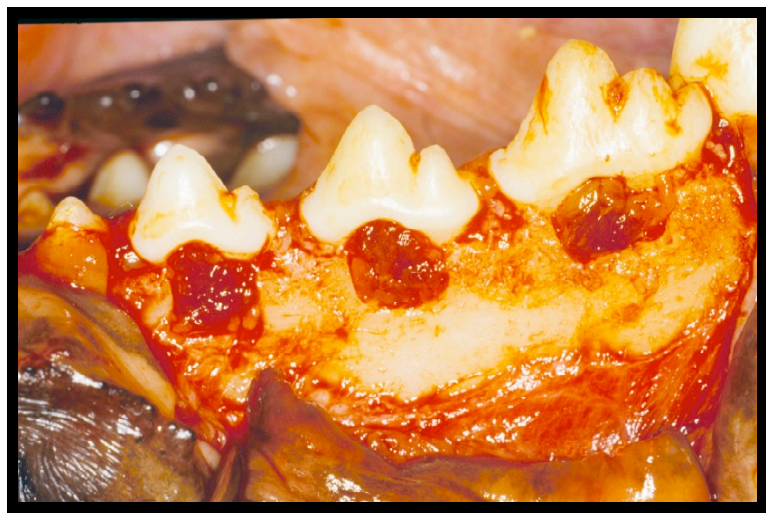

Figura 4.1 - Defeitos de furca classe II criados preenchidos com enxerto

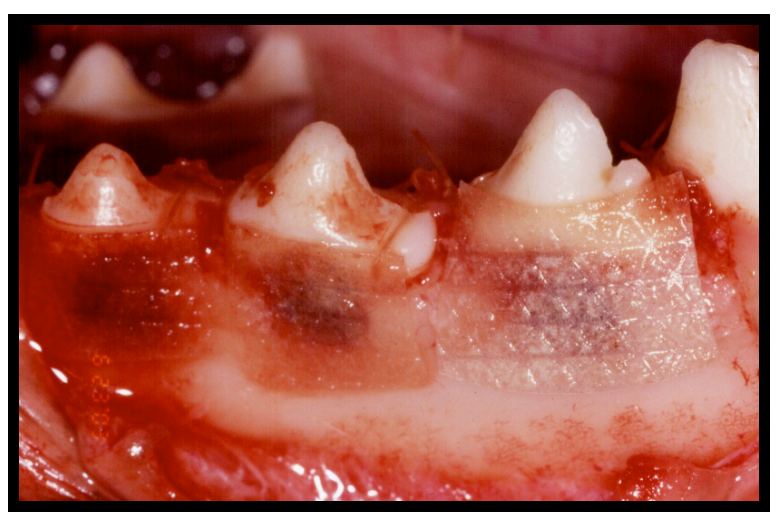

Figura 4.2 - Membranas posicionadas e estabilizadas 
Para diminuir o risco de infecões pós-operatórias alguns cuidados foram tomados. Após as cirurgias, foi administrado antibiótico e antinflamatório para todos os cães e, diariamente realizou-se a aplicação tópica de digluconato de clorexidina a $0,12 \%$. Após um período de 45 dias os cães foram sacrificados.

O material coletado dos cães foi descalcificado em EDTA a 10\%. Após a completa descalcificação, as amostras de cada dente foram seccionadas no sentido vestíbulo-lingual no centro da furca e, incluídos em parafina. Dois blocos de parafina de cada cão, contendo um defeito do grupo controle e um do teste, correspondendo às porções distais dos terceiros pré-molares esquerdos e direitos, foram utilizados neste estudo. Os blocos foram codificados para cegar o experimento e, após isto, foram cortados no micrótomo. Cortes com espessura de 5 micrômetros foram obtidos e estendidos em lâminas de vidro silanizadas e, posteriormente submetidos ao processamento imuno-histoquímico.

\subsection{Processamento imuno-histoquímico}

As reações imuno-histoquímicas contra os componentes não colágenos da matriz extracelular (MEC) foram realizadas utilizando os seguintes anticorpos policlonais desenvolvidos em coelho: anticorpos para osteonectina (BON-I), anticorpos para osteopontina humana (LF-166) e o anticorpo para sialoproteína óssea (LF-84) (FISHER et al., 1987), gentilmente cedidos e recomendados pelo Dr Larry W. Fisher, Matrix Biochemistry Unit, Craniofacial and Skeletal Branch, National 
Institute of Health, Bethesda, MD, USA. Os clones, titulação e tempo de incubação dos anticorpos estudados estão indicados na tabela 4.1.

Tabela 4.1 - Clone, título de tempo de incubação dos anticorpos primários

\begin{tabular}{cccc}
\hline Anticorpo & Código & Título & Tempo de incubação \\
\hline Osteonectina & BON-I & $1: 900$ & $60^{\prime}$ \\
\hline Osteopontina & LF-166 & $1: 250$ & $60^{\prime}$ \\
\hline Sialoproteína óssea & LF-84 & $1: 750$ & $90^{\prime}$ \\
\hline
\end{tabular}

Foi seguido o protocolo para a técnica imuno-histoquímica estabelecido pelo Laboratório de Patologia Cirúrgica da Disciplina de Patologia Bucal na FOUSP:

1. Desparafinização em 2 banhos de xilol: (1) por 30 minutos à temperatura de $60^{\circ} \mathrm{C}$; e (2) por 20 minutos à temperatura ambiente.

2. Reidratação em uma série de etanol em concentrações decrescentes (absoluto por 3 vezes, 95\%, 85\%) em banhos de 5 minutos cada, realizando, ao final, um banho de 10 minutos em hidróxido de amônio a 10\% em etanol 95\% para a remoção de pigmentos formólicos, seguidos de 10 minutos em água corrente e 2 banhos em água destilada.

3. Bloqueio da peroxidase endógena com solução de peróxido de hidrogênio a $6 \%$ em metanol na proporção de 1:1, em 2 banhos de 15 minutos cada.

4. Lavagem em água corrente por 10 minutos e 2 banhos em água destilada.

5. Dois banhos em solução tampão de TRIS-HCL (hidroximetil-amino-metano) a $0,5 \mathrm{M}, \mathrm{pH} 7.4$, cinco minutos cada imersão.

8. Incubação com soro suíno normal, diluído a 30\% em BSA, (Dako Corp. ${ }^{\circledR}$, Carpinteria, CA), em câmara úmida, por 60 minutos para OPN e BON e por 90 minutos para BSP, para bloqueio dos sítios antigênicos inespecíficos. 
Após estas etapas, todos os cortes seguiram para o equipamento DAKO Autostainer Universal Staining System (DAKO Corp. ${ }^{\circledR}$, Carpinteria, CA, USA), onde se concluiu a reação com o seguinte protocolo:

1. Incubação dos anticorpos primários sob temperatura controlada a $37^{\circ} \mathrm{C}$.

2. Incubação com o complexo terciário estreptavidina-biotina (Kit LSAB Peroxidase K0690 - Dako Corp.®, Carpinteria, CA, USA).

3. Revelação da reação com DAKO Liquid DAB plus (cód. K3468) (Dako Corp.®, Carpinteria, CA, USA).

4. Contra-coloração com hematoxilina de Mayer.

Entre cada uma das reações realizadas automaticamente, os cortes foram lavados duas vezes em TBST.

A seguir, todos os cortes foram desidratados numa série de etanol em concentrações crescentes $(80 \%, 95 \%$ e 3 vezes em álcool absoluto) por 5 minutos cada e em seguida, diafanizados em xilol, seguindo para montagem final.

\subsection{Método de análise do material}

As lâminas foram analisadas em microscópio de luz por um observador calibrado, para identificar a presença ou ausência de marcação para cada proteína e seu padrão de marcação nos tecidos pré-existentes do lado lingual e nos tecidos reparativos neoformados no interior dos defeitos periodontais.

A imunorreatividade foi determinada na vestibular (lado do defeito) e na lingual de cada peça. Na vestibular, o exame compreendeu as matrizes do tecido 
conjuntivo do defeito, do novo cemento e do novo osso e, para o lado lingual, foram avaliadas as matrizes do osso pré-existente, do cemento, do ligamento periodontal e do tecido conjuntivo. As células dos tecidos reparativos do lado vestibular relacionadas ao novo osso, novo cemento e ao tecido conjuntivo também foram avaliadas quanto à marcação bem como os cementócitos, cementoblastos, osteócitos, osteoblastos, células do ligamento periodontal e do tecido conjuntivo do lado lingual das amostras. As marcações para foram consideradas negativas (-), fracamente positivas $(+)$, positivas $(++)$ ou fortemente positivas $(+++)$ de acordo com a intensidade de impregnação da substância cromógena. Este método de análise foi baseado no modelo proposto por Ivanovski et al. (2000). 


\section{RESULTADOS}

O período pós-cirúrgico transcorreu sem grandes intercorrências e os animais foram sacrificados para obtenção das amostras e realização dos cortes histológicos. Apenas no cão 4 foi notada, macroscopicamente, a deiscência do retalho após uma semana pós-cirúrgica, ficando as membranas expostas ao meio bucal.

\subsection{Descrição Geral dos Eventos Observados nas Lâminas}

No geral os eventos relacionados à reparação foram semelhantes nos grupos teste e controle. Houve formação de novo osso, novo cemento e tecido conjuntivo nos defeitos criados cirurgicamente. No lado lingual dos espécimes estavam presentes osso maduro, cemento, ligamento peridontal e tecido conjuntivo gengival. (Figura 5.1). Novo osso em maior quantidade foi encontrado no fundo do defeito na porção apical. Ao redor das membranas foi encontrado infiltrado inflamatório inespecífico. 


\subsection{Marcação pela ONC}

No lado lingual, nos grupos teste e controle, para a ONC houve marcação heterogênea apenas na matriz óssea e, quando presente, esta marcação foi fraca. Nos defeitos criados cirurgicamente houve marcação no cemento e osso (matriz e células) e uma tendência para a não marcação do tecido conjuntivo dos defeitos (células e matriz) (Figura 5.2). Quanto ao osso, as células e a matriz óssea nos defeitos tratados nos grupos controle e teste apresentaram marcação tendendo ao moderado (Figuras 5.2 e 5.3). A matriz do novo cemento tanto no grupo teste quanto controle e os cementoblastos do grupo teste tiveram marcação leve, já os cementoblastos do grupo controle tiveram marcação moderada (Figura 5.4). O padrão de marcação encontra-se naTabela 5.1 .

Em ambos os grupos a espessura do cemento encontrada foi delgada com uma camada de células arredondadas sobre sua superfície (Figura 5.4). Nos espécimes observados foi possível identificar uma linha marcada entre o novo cemento e a dentina. O osso lamelar no lado lingual demonstrou ser um osso normal com sistemas harvesianos e linhas de cemento circundando-os (Figura 5.5). Na interface novo osso e antigo, as linhas de reversão não ficaram fortemente marcadas, mas no geral, foi possível visualisar além da diferença morfológica do novo osso uma diferença de marcação imuno-histoquímica entre o novo osso e o osso pré-existente (Figura 5.6). Osteoclastos estavam presentes no novo osso porém não foram marcados (Figura 5.7). Osteoblastos arredondados estavam presentes sobre a superfície óssea sugerindo atividade. 


\subsection{Marcação pela OPN}

No lado lingual o tecido conjuntivo foi marcado apenas no grupo controle (Figura 5.8) e, cementócitos e osteócitos não foram marcados em ambos os grupos. Com exceção da matriz óssea que apresentou uma marcação semelhante entre teste e controle, quando presente a marcação foi mais forte no grupo controle. Tal fato repetiu-se no grupo teste para os parâmetros analisados. O padrão de marcação encontra-se na Tabela 5.2.

Como não houve uma diferença marcante na quantidade de marcação entre o osso pré-existente do lado lingual e o novo osso no defeito. A visualização do novo osso foi feita através do exame morfológico. Nas superfícies do novo osso (Figura 5.9) e novo cemento (Figura 5.10), e na interface novo cemento e dentina foi perceptível uma camada mais marcada tanto no grupo teste quanto controle (Figura 5.10). No geral, linhas de reversão não foram encontradas. No osso pré-existente o aspecto foi de normalidade. 


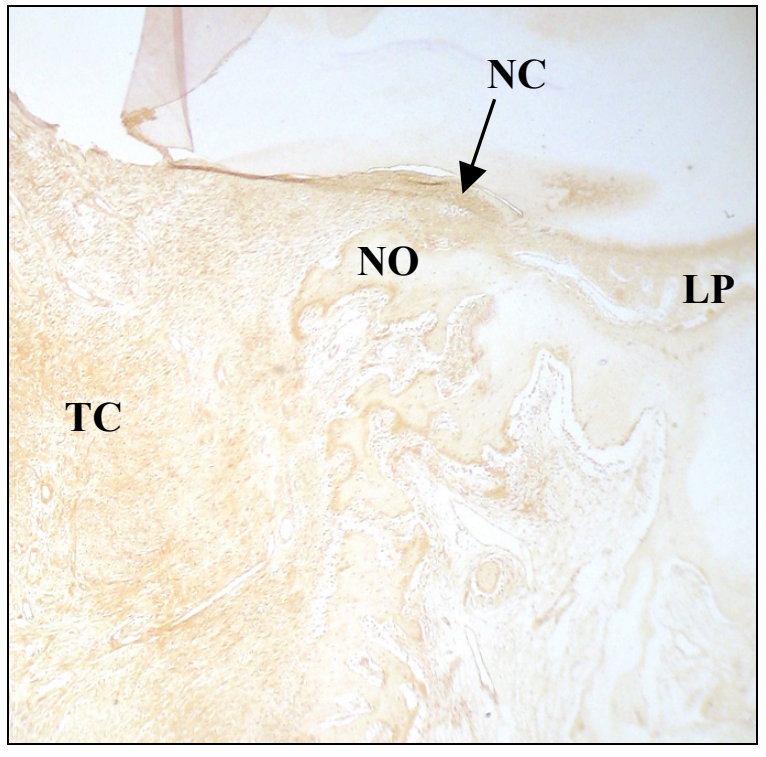

Figura 5.1 - Imuno-histoquímica para BSP (cão A - lado teste) demonstrando marcação no novo osso (NO), novo cemento (NC), tecido conjuntivo (TC) e ligamento periodontal pré-existente (LP) $(2,5 \mathrm{X})$

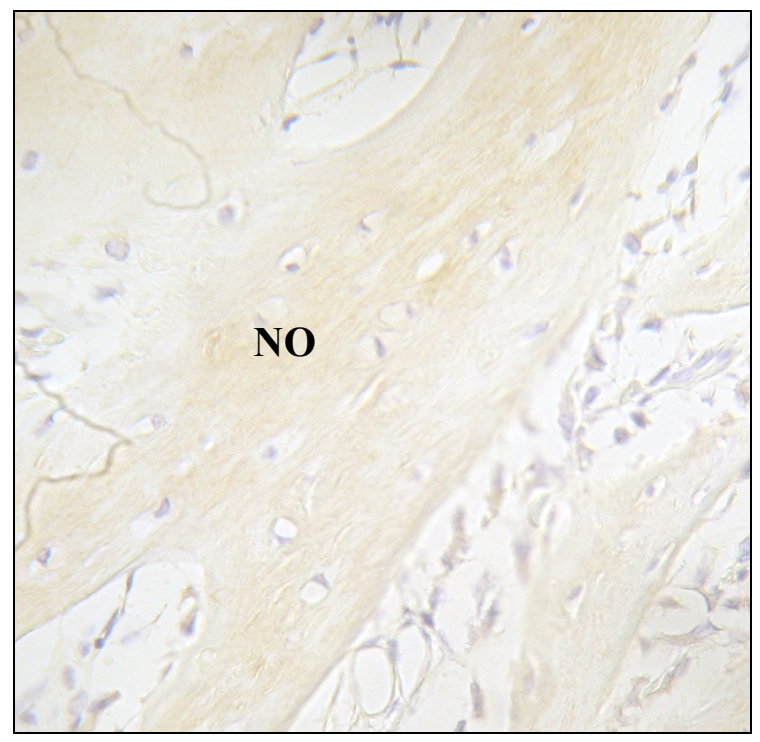

Figura 5.3 - Imuno-histoquímica para ONC (cão B - lado controle) demonstrando marcação moderada no tecido ósseo neoformado (NO) (10X)

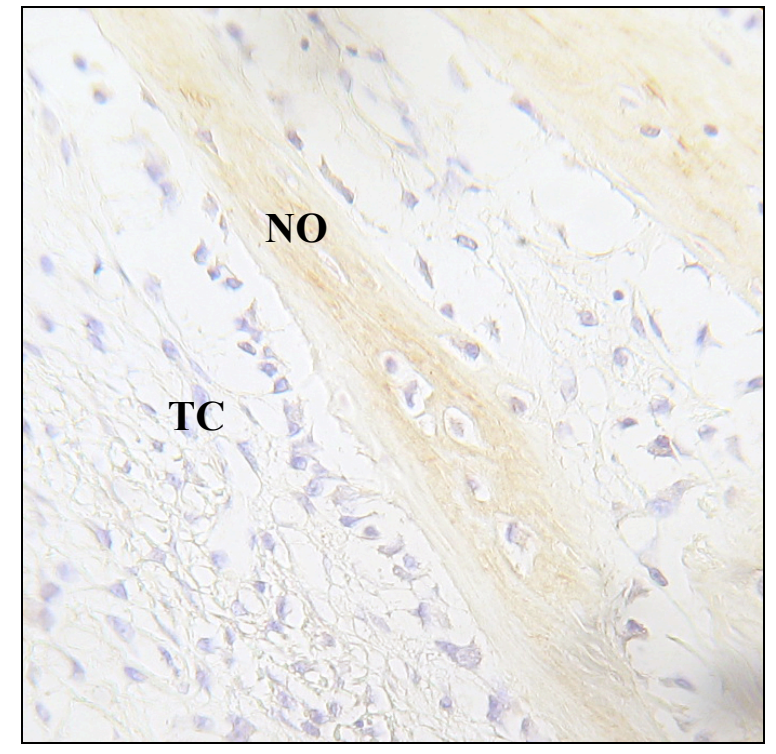

Figura 5.2 - Imuno-histoquímica para ONC (cão B - lado teste) demonstrando marcação negativa para $\mathrm{o}$ tecido conjuntivo (TC) e marcação moderada no tecido ósseo neoformado (NO) (10 X)

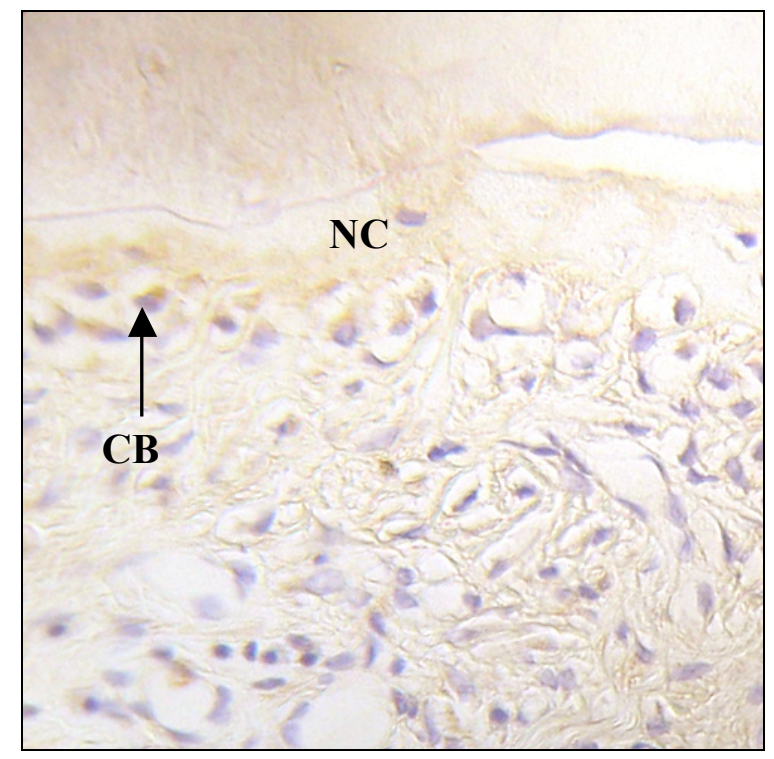

Figura 5.4 - Imuno-histoquímica para ONC (cão A - lado teste) demonstrando marcação do novo cemento (NC) e cementoblastos (CB) (40X) 


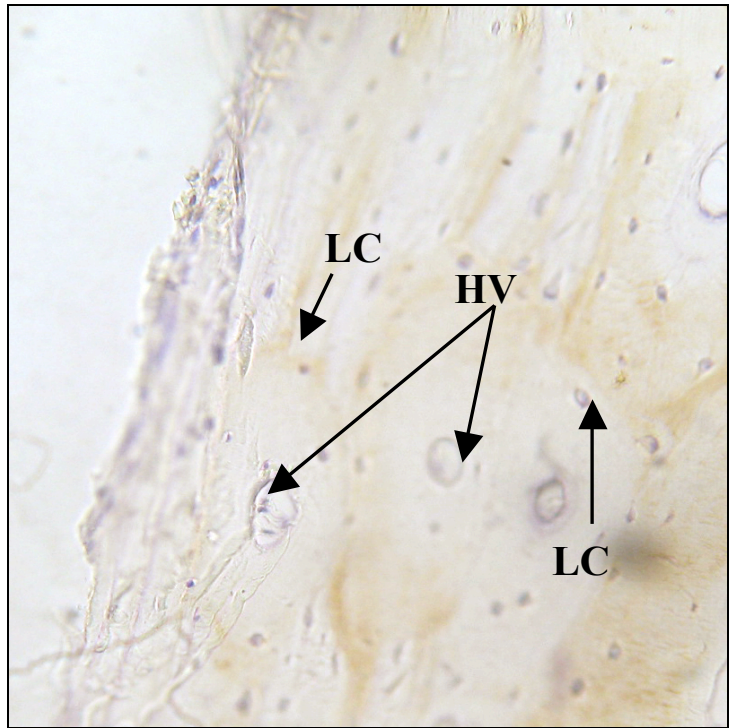

Figura 5.5 - Imuno-histoquímica para ONC (cão D - lingual) notar os canais harvesianos (HV) e linhas de cemento (LC) circundando-os (10X)

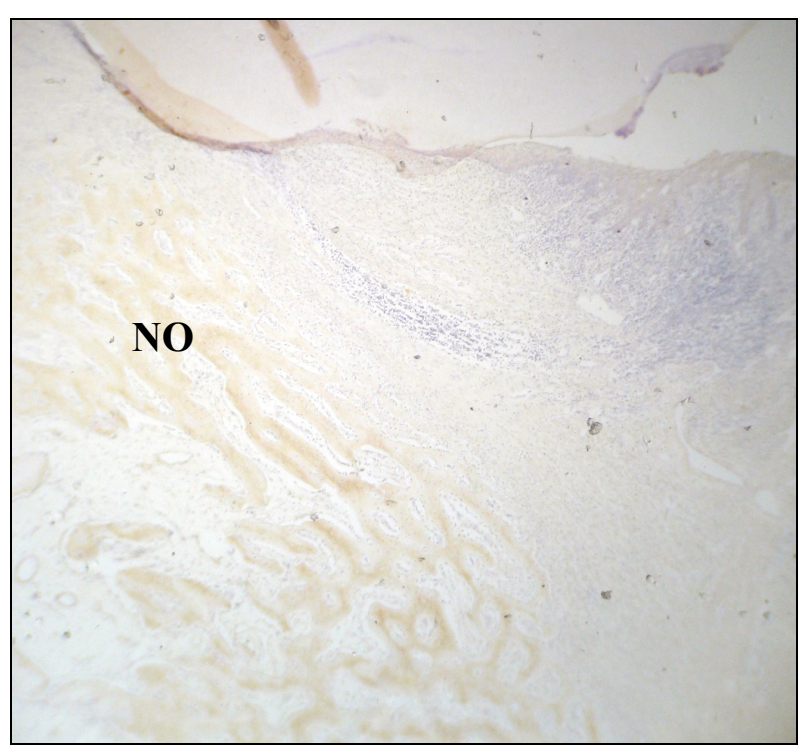

Figura 5.6 - Imuno-histoquímica para ONC (cão D - lado teste) com o novo osso (NO) marcado em coloração mais forte $(2,5 \mathrm{X})$

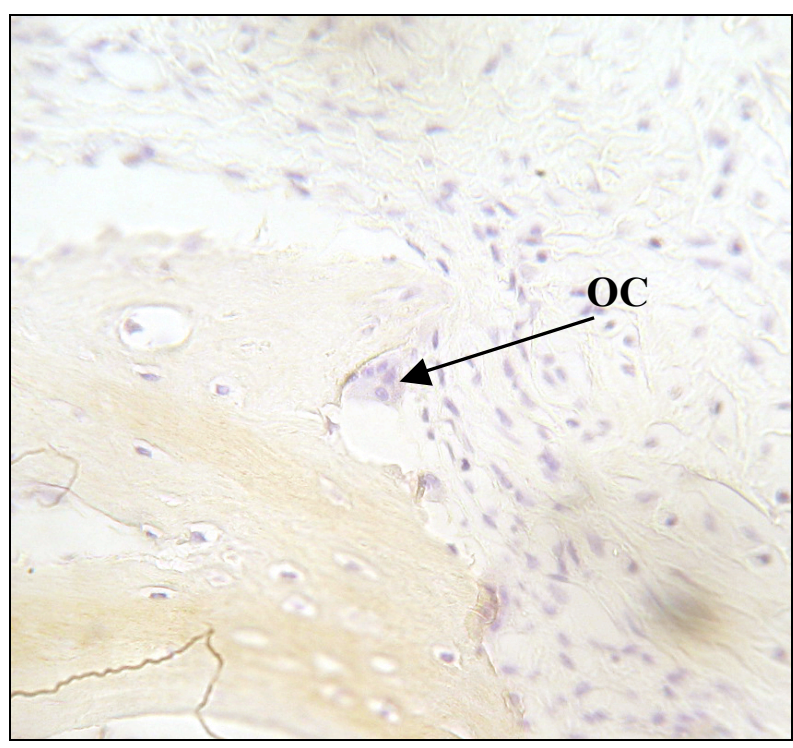

Figura 5.7 - Imuno-histoquímica para ONC (cão D - lado controle) onde o osteoclasto (OC) não foi marcado $(10 \mathrm{X})$ 


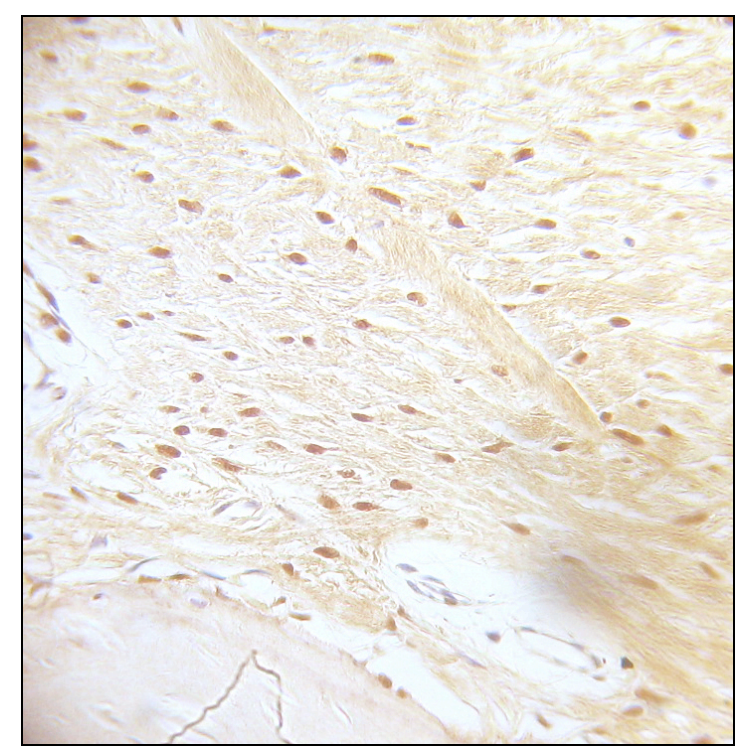

Figura 5.8 - Imuno-histoquímica para OPN (cão A - lado controle) demonstrando marcação para o osso pré-existente (O) e tecido conjuntivo (TC) tecido notar os canais (10X)

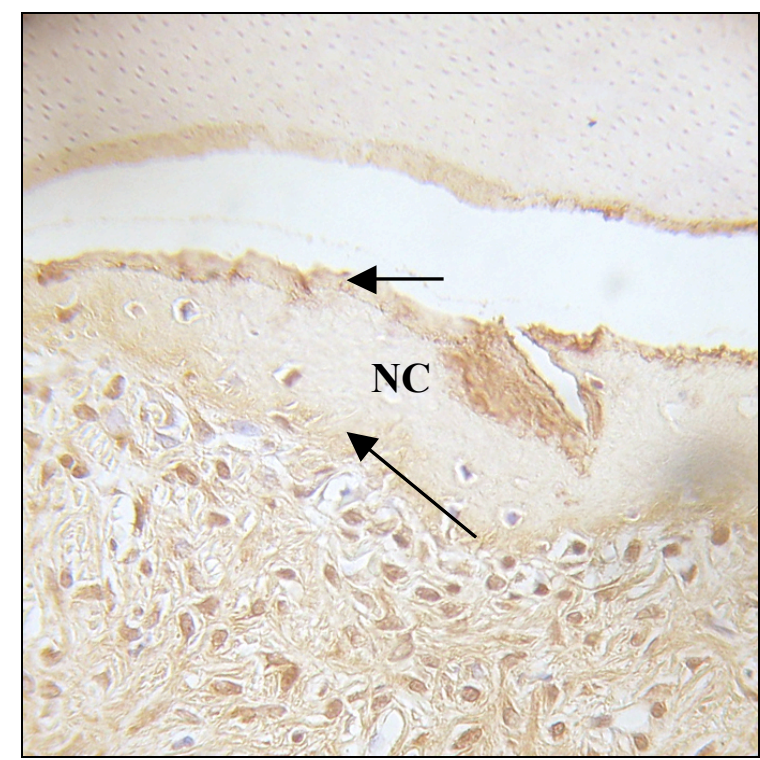

Figura 5.10 - Imuno-histoquímica para OPN (cão A - lado controle) demonstrando linhas mais marcadas sobre 0 novo cemento (NC) (seta maior) e entre a dentina e o novo cemento (seta menor) (40X)

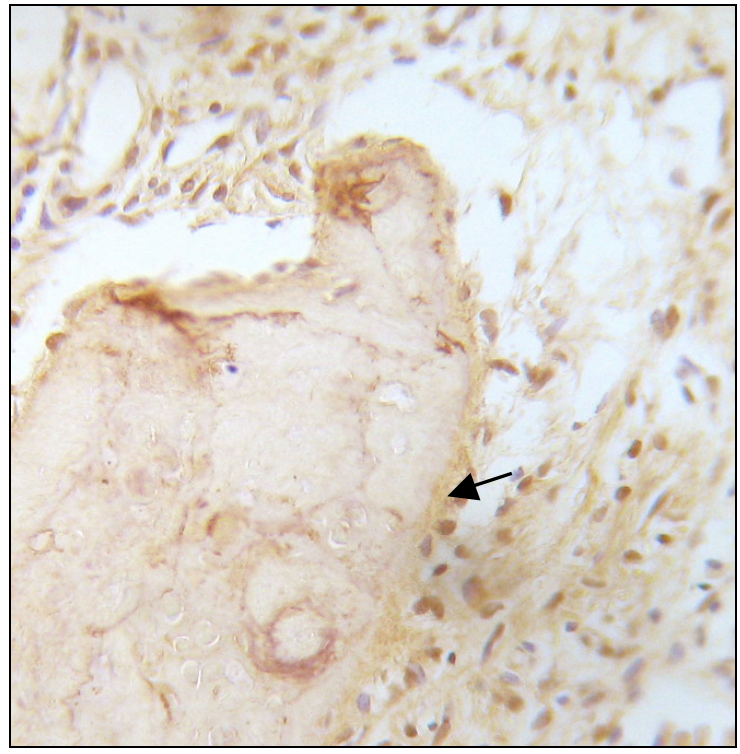

Figura 5.9 - Imuno-histoquímica para OPN (cão D - lado controle) demonstrando uma linha de marcação (seta) sobre a superfície do novo osso (NO) (10X) 


\subsection{Marcação pela BSP}

Nas faces linguais dos defeitos a marcação para a BSP foi semelhante para o tecido conjuntivo, cemento e osso. No ligamento periodontal não houve marcação nas células do grupo controle ao contrário do grupo teste onde esta marcação foi moderada. Nos tecidos em reparação tanto no grupo teste quanto no controle o padrão de marcação foi igual para todos os parâmetros a exceção das células do novo cemento que no grupo controle foi mais forte que no grupo teste (Tabela 5.3).

Na superfície do novo osso foi encontrada uma marcação mais evidente bem como nas células que a recobriam (Figura 5.11). No osso lingual ao defeito isto era menos evidente e as células sobre a superfície óssea também tiveram menor marcação (Figura 5.12). No geral, linhas de reversão foram encontradas. O novo cemento teve coloração mais escura que o osso sendo que uma linha mais marcante foi encontrada em sua superfície. Na interface dentina-novo cemento a linha que os separavam foi pouco evidente (Figura 5.13). Osteoclastos foram encontrados no novo osso e, nestas áreas foi comum encontrar um aumento na marcação. Os osteócitos recém aprisionados na matriz óssea apresentaram marcação enquanto que osteócitos em osso menos imaturos a coloração tendeu a não ocorrer. 


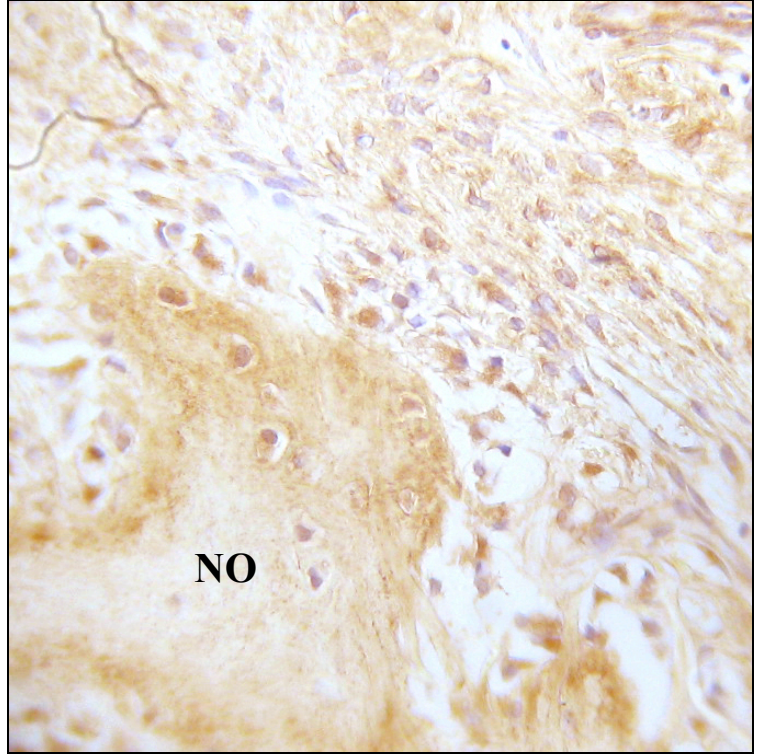

Figura 5.11 - Imuno-histoquímica para BSP (cão A - lado teste) demonstrando marcação no novo osso (NO) com células que recobrem sua superfície e em seu interior também marcadas (40X)

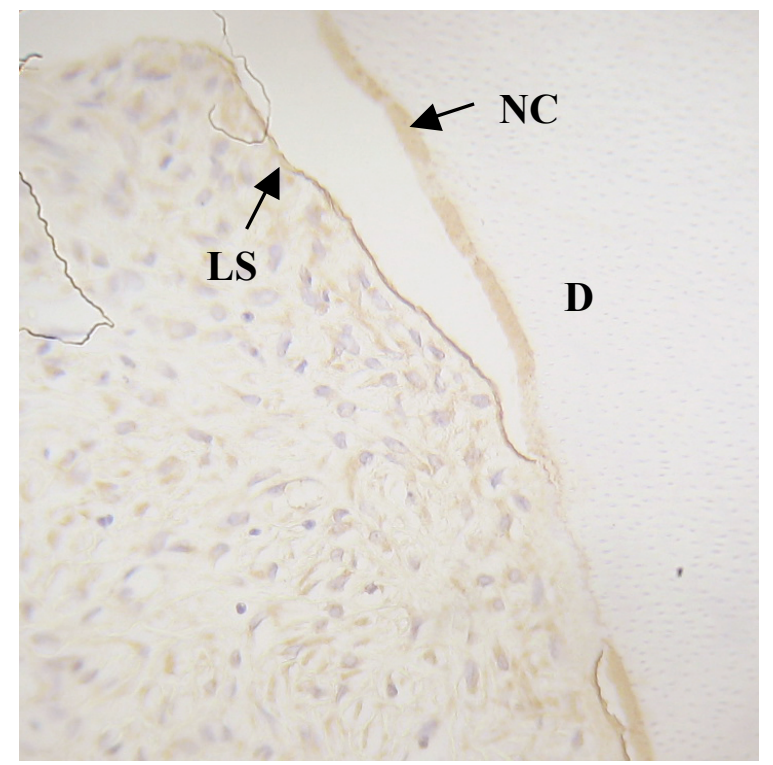

Figura 5.13 - Imuno-histoquímica para BSP (cão A - lado controle) demonstrando marcação mais acentuada formando uma linha superficial (LS) sobre o novo cemento (NC) e ausência de marcação da dentina (D) (10X)

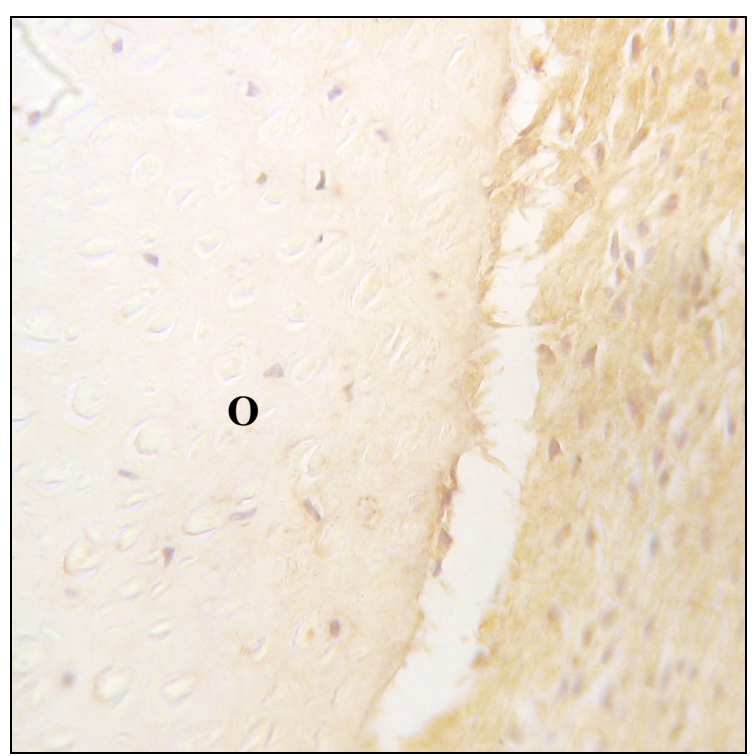

Figura 5.12 - Imuno-histoquímica para BSP (cão A - lingual) demonstrando marcação do osso pré-existente $(O)$ menos evidente comparada à marcação do novo osso na Figura $5.11(10 \mathrm{X})$ 
Tabela 5.1 - Resultados representativos da marcação por imuno-histoquímica para ONC. $(-), \quad(+), \quad(++), \quad(+++)$ e $(+/-)$ correspondem à marcação ausente, fraca, média, forte e heterogênea respectivamente

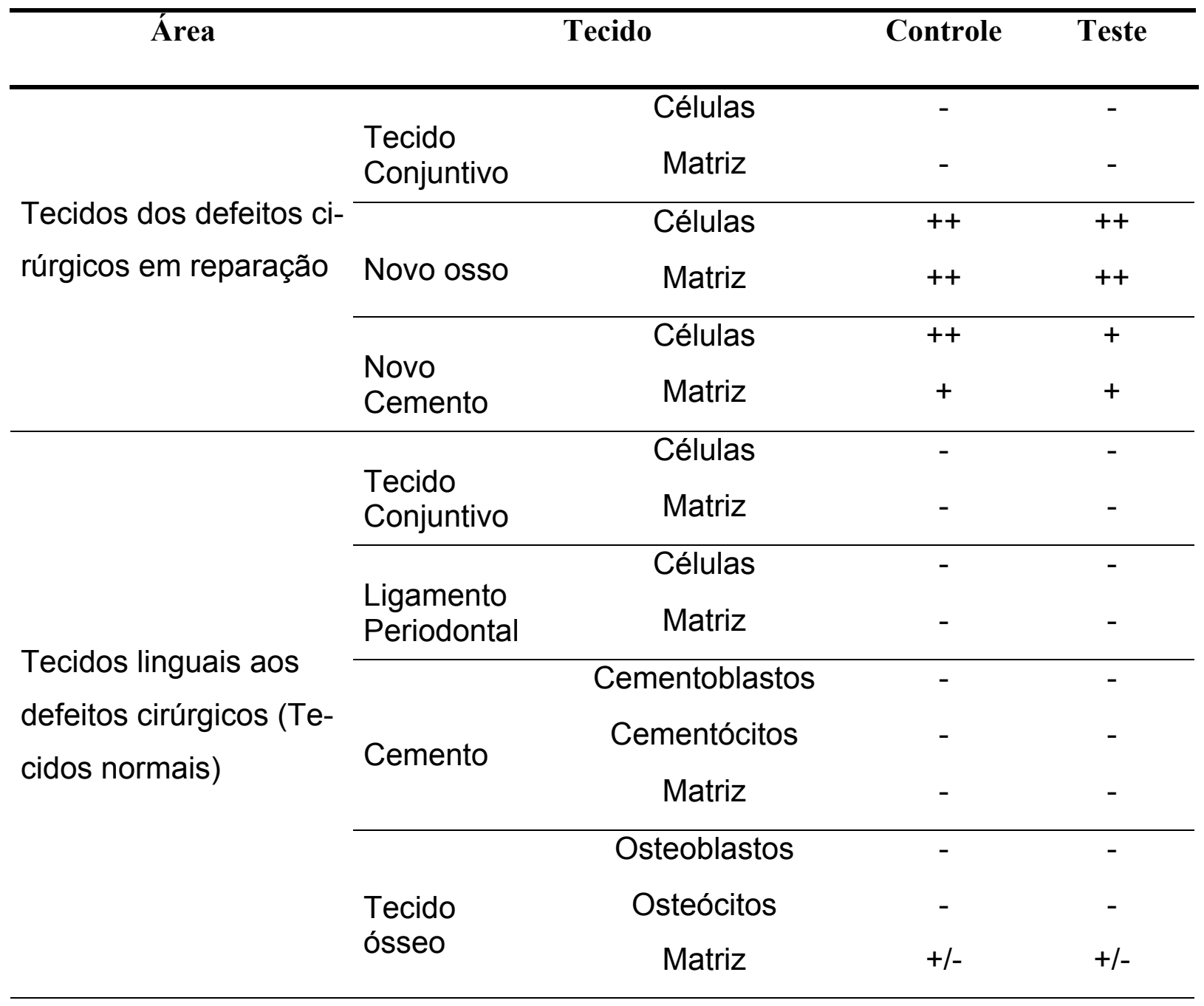


Tabela 5.2 - Resultados representativos da marcação por imuno-histoquímica para OPN. (-), (+), (++) e (+++) correspondem à marcação ausente, fraca, média e forte respectivamente, $(++/-)$ e $(+++/-)$ correspondem à marcação heterogênea

\begin{tabular}{|c|c|c|c|c|}
\hline Área & & Tecido & Controle & Teste \\
\hline \multirow{6}{*}{$\begin{array}{l}\text { Tecidos dos defeitos ci- } \\
\text { rúrgicos em reparação }\end{array}$} & & Células & $+++/-$ & $++/-$ \\
\hline & Conjuntivo & Matriz & +++ & $++/-$ \\
\hline & & Células & +++ & ++ \\
\hline & Novo osso & Matriz & ++ & ++ \\
\hline & & Células & ++ & + \\
\hline & $\begin{array}{l}\text { Novo } \\
\text { Cemento }\end{array}$ & Matriz & ++ & + \\
\hline \multirow{10}{*}{$\begin{array}{l}\text { Tecidos linguais aos } \\
\text { defeitos cirúrgicos (Te- } \\
\text { cidos normais) }\end{array}$} & & Células & ++ & - \\
\hline & $\begin{array}{l}\text { Tecido } \\
\text { Conjuntivo }\end{array}$ & Matriz & +++ & - \\
\hline & & Células & +++ & + \\
\hline & $\begin{array}{l}\text { Ligamento } \\
\text { Periodontal }\end{array}$ & Matriz & +++ & + \\
\hline & \multirow{3}{*}{ Cemento } & Cementoblastos & +++ & + \\
\hline & & Cementócitos & - & - \\
\hline & & Matriz & + & + \\
\hline & \multirow{3}{*}{$\begin{array}{l}\text { Tecido } \\
\text { ósseo }\end{array}$} & Osteoblastos & +++ & + \\
\hline & & Osteócitos & - & - \\
\hline & & Matriz & ++ & ++ \\
\hline
\end{tabular}


Tabela 5.3 - Resultados representativos da marcação por imuno-histoquímica para BSP. (-), (+), (++) e (+++) correspondem à marcação ausente, fraca, média e forte respectivamente

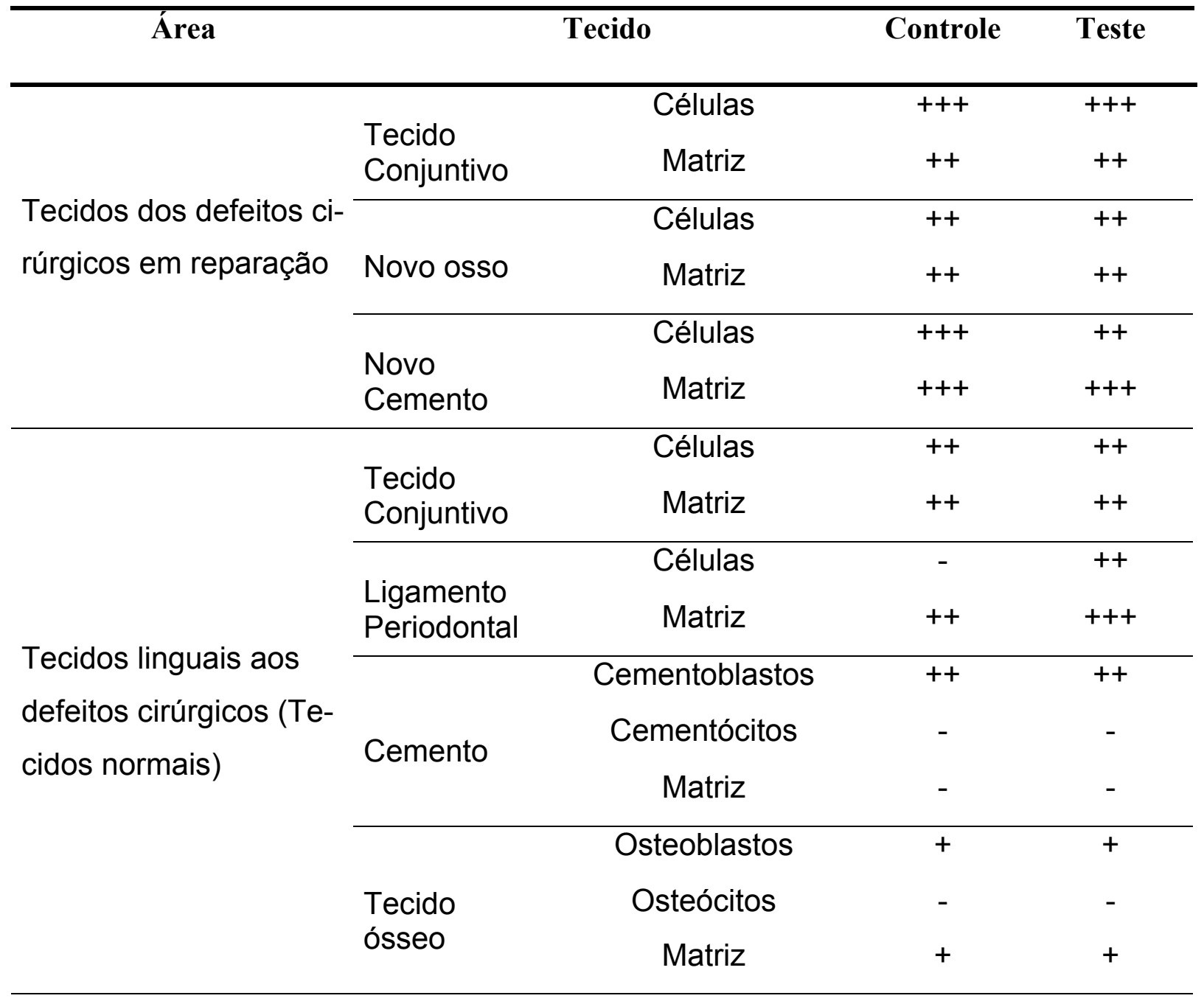




\section{DISCUSSÃO}

Os trabalhos que estudam a utilização de técnicas regenerativas em defeitos periodontais de animais, tem como um dos principais problemas a padronização dos defeitos a serem tratados, o que é necessário para que se tenha uma análise comparativa dos resultados mais acurada.

A dificuldade de se obter defeitos periodontais naturais que padronizados fez com que os pesquisadores criassem, artificialmente, defeitos periodontais. Assim, os pesquisadores que não utilizam defeitos naturais, tentam padronizar os defeitos artificialmente, fazendo-os em um ou dois estágios. Quando o fazem em um estágio, criam, através de instrumentação cirúrgica, um defeito periodontal ao redor da raiz, e a partir deste momento testam o potencial de reparação frente à alguma técnica cirúrgica. Este defeito é considerado agudo. Nos defeitos criados em dois estágios, após criado o defeito agudo, este é cronificado pelo acúmulo de placa e, ainda, é colocado algum tipo de material no seu interior para que não haja regeneração espontaneamente. Após um certo período, o material que impede a reparação é removido, faz-se o desbridamento da área por meio de raspagem e alisamento corono-radicular e o controle de placa é retomado. Quando os sinais de inflamação cessam, os defeitos sofrem as cirurgias para se testar o potencial de reparação de uma técnica cirúrgica. Os autores que defendem os estudos com defeitos artificiais preconizam a remoção de todo o cemento radicular nestas áreas antes da aplicação da técnica regenerativa que se quer testar. Isto porque, nos defeitos naturais, a presença da placa bacteriana faz com que o cemento radicular fique impregnado com endotoxinas e, a remoção destas endotoxinas, placa bacteriana e cálculo 
dentário são imprescindíveis para a realização de técnicas regenerativas. Assim, para se obter uma superfície limpa, a raiz deve ser instrumentada, o que faz com que quase todo o cemento seja removido. Como o cemento é removido em ambos os defeitos, naturais, crônicos ou agudos e a sua neoformação é imprescindível para a regeneração periodontal, é possível se testar o potencial regenerativo das técnicas nestes diferentes tipos de defeitos (WIKESJÖ; SELVIG, 1999). O modelo escolhido em nosso estudo foi o do defeito periodontal agudo.

Nossa intenção, entretanto, não é afirmar que o modelo agudo é o melhor para se estudar a reparação de defeitos periodontais, e sim um modelo para se comparar o potencial reparativo de duas técnicas, em defeitos periodontais cirúrgicos padronizados.

Em uma ou duas semanas a reparação das feridas, após as cirurgias periodontais, já apresenta formação de tecido conjuntivo, porém a formação de cemento, que é necessária para a inserção conjuntiva, ocorre dentro de pelo menos 3 semanas. Neste estudo optou-se pelo período de reparação de 45 dias, pois nesta fase existiria consideráveis quantidades de novo cemento e osso (SELVIG, 1994).

Estudos que observaram a reparação do defeito periodontal, após cirurgia, demonstraram que a regeneração não é previsível, porque na maiora das vezes ocorre a formação de epitélio juncional longo que, impede a inserção de fibras colágenas à raiz. Assim, por vezes encontra-se nova formação de osso, mas com epitélio juncional entre este e a raiz inexiste a regeneração do ligamento periodontal (LISTGARTEN; ROSENBERG, 1979; CATON; NYMAN; ZANDER, 1980).

A extensão da migração do epitélio juncional em direção apical, parece estar relacionada com as fases iniciais de reparação das feridas periodontais. Após a cirurgia periodontal existe a formação de um coágulo de fibrina na área do defeito 
periodontal. Este fica levemente aderido à superfície radicular e, aparentemente, esta união é de suma importância para o resultado final da reparação, pois alguns estudos demonstraram que em áreas onde este coágulo é estabilizado a migração do epitélio juncional ocorre em menor extensão (WIKESJÖ; NILVÉUS; SELVIG, 1992; GARRETT, 1994).

Tradicionalmente, a utilização do enxerto ósseo levando à regeneração é explicada pela capacidade indutora do material inserido no defeito, mas, pensandose na estabilização do coágulo, o enxerto ósseo pode funcionar como um suporte para a formação do coágulo, melhorando sua estabilização (WISKESJÖ; NILVÉUS; SELVIG, 1992). A RTG, que visa primariamente excluir o epitélio e o tecido conjuntivo do contato com a raiz, tentando previlegiar as células provenientes do osso e do ligamento periodontal, pode, também, proteger o coágulo de influências externas. O retalho deslocado coronariamente também acaba por proteger este coágulo, uma vez que tenta diminuir a retração do retalho que poderia expor o coágulo ao meio externo, prejudicando sua adesão (GARRETT, 1994). Em nosso estudo, tentamos associar as técnicas de retalho deslocado coronariamente, RTG e enxerto de osso imaturo para averiguação de um possível efeito aditivo entre as técnicas, comparando-as ao retalho deslocado coronariamente puro.

Estudos que utilizaram enxertos ósseos em defeitos periodontais demonstram, geralmente, aumento na quantidade de formação de novo osso em relação aos defeitos tratados sem os enxertos ósseos (BRUNSVOLD; MELLONIG, 1993). A razão da utilização dos enxertos baseia-se no potencial de osteogênese, osteocondução e osteoindução que estes podem apresentar (AMLER, 1984, KARRING; LINDHE; CORTELLINI, 1999). 
Entre os enxertos ósseos autógenos, o de osso imaturo seria o ideal, pois possui um potencial de indução de formação óssea (AMLER, 1984; PASSANEZI et al. 1989). Nos estudos em cães, realizados na Disciplina de Periodontia da Faculdade de Odontologia da Universidade de São Paulo e que precederam este estudo, foi encontrada formação de osso com certo grau de maturação aos 14 dias (CORDIOLI, 1999) e aos 10 dias em alvéolos em reparação pós exodontia (CORDIOLI, 2002; DE VUONO, 2002; FERRARO, 2002). Baseando-se nestes estudos predecessores, em nosso estudo optou-se pelo teste de um tecido mais imaturo para enxertia, com 5 dias de reparação pós-exodontia. Nesta fase inicia-se a formação novo osso na periferia do alvéolo (CLAFIN, 1936).

Geralmente, a posição da margem do retalho, após a cirurgia periodontal, é posicionada por sutura em uma altura muito próxima a área onde se tenta obter a regeneração. A mobilidade da margem do retalho pode interferir na adesão do coágulo em reparação, rompendo-a e permitindo a migração do epitélio juncional por sobre a raiz (GARRETT; BOGLE, 1993). O retalho deslocado coronariamente tem sido advogado para os procedimentos que visam a regeneração periodontal de áreas de furca, pois o afastamento da borda do retalho da área da ferida periodontal, retardaria o processo de migração do epitélio juncional. Este posicionamento também diminuiria o risco de que a mobilidade da margem do retalho prejudicasse a estabilidade do coágulo em reparação e ainda, tal afastamento poderia proteger as membranas de RTG ou enxertos quando utilizados (GARRETT; BOGLE, 1993; LEKOVIC, 1990).

Trabalhos em humanos, que compararam o retalho deslocado corornariamente com a RTG demonstraram uma semelhança de resultados, porém, quando se adicionou o enxerto de hidroxiapatita à RTG o grau de preenchimento 
ósseo foi superior ao posicionamento coronal de retalho apenas, embora outros parâmetros como profundidade clínica de sondagem e nível de inserção clínica não tenham mostrado diferenças estatisticamente significantes (ANDERSSON et al., 1994, GANTES et al., 1988; LEKOVIC et al., 1990). Tais trabalhos, entretanto, foram realizados em humanos, não contendo análise histométrica, sendo comparados apenas parâmetros clínicos ou o grau de preenchimento ósseo acessados por cirurgia de reentrada.

Normalmente os trabalhos que utilizam a RTG em dentes com defeitos de furca grau II em animais utilizam o retalho reposto ou o retalho levemente deslocado coronariamente, o suficiente para se recobrir as membranas. Um trabalho semelhante ao nosso é o de Bogle et al. (1997). Seus resultados histométricos, para o grupo controle, foram de $18 \%$ de neoformação de tecido conjuntivo, $17 \%$ de cemento, $13,5 \%$ de novo osso e $82 \%$ de epitélio juncional. Para o grupo teste os resultados foram de $78 \%$ de neoformação de tecido conjuntivo, $69 \%$ de cemento, $74 \%$ de novo osso e $22 \%$ de epitélio juncional. Em nosso experimento anterior (HAYASHI, 2004), no grupo controle ocorreram $78 \%$ de neoformação de tecido conjuntivo, $45 \%$ de cemento, $36 \%$ de novo osso e $18 \%$ de epitélio juncional, e para o grupo teste ocorreram $80 \%$ de neoformação de tecido conjuntivo, $41 \%$ de cemento, $20 \%$ de novo osso e $20 \%$ de epitélio juncional. As diferenças mais evidentes, comparando-se nosso estudo ao de Bogle et al. (1997), estão entre os grupos controles, sendo que em nosso experimento os resultados foram mais substanciais. A causa proválvel seria o uso do retalho deslocado coronariamente ao invés do retalho reposto como o do trabalho citado. Corroboram com esta idéia outros estudos realizados por nós onde foram utilizados o RDC (SOARES et al., 2005; YORIOKA, 2004). 
Como dito anteriormente, a proximidade da margem do retalho à ferida periodontal pode interferir negativamente na reparação, assim, os grupos controles dos trabalhos que compararam a RTG ao retalho reposto, podem ter sido prejudicados por esse motivo, enquanto que as membranas podem ter protegido a área em reparação a despeito da proximidade da margem do retalho. Em nosso trabalho o deslocamento foi acentuado, ficando a margem do retalho bastante afastada do defeito em reparação.

A opção pela utilização de membrana absorvível ao invés de uma não absorvível se deveu ao fato de a literatura relatar resultados semelhantes para ambas (CAFFESSE et al., 1994; MAGNUSSON; BATICH; COLLINS, 1988). Outra vantagem é a de não ser necessário um segundo procedimento cirúrgico para a remoção da mesma.

O corte histológico no sentido vestíbulo-lingual é mais favorável para análise que os cortes no sentido mésio-distal, pois nestes últimos fica difícil estabelecer o plano de corte em termos de angulação e profundidade e ainda de se ter uma noção mais real da reparação, pois deve-se criar uma imagem tridimensional da região utilizando-se cortes de diferentes profundidades (BOGLE et al., 1997).

Era esperado que, no grupo teste, ocorressem resultados mais favoráveis que no grupo controle devido a um efeito aditivo entre os tratamentos de RTG e enxerto ósseo, porém, estatisticamente, os resultados foram semelhantes aos do grupo controle em termos de migração de epitélio juncional, novo cemento e tecido conjuntivo. Na formação de novo osso os resultados demonstram que este ocorreu em menor quantidade no grupo teste, embora esta diferença não tenha sido estatisticamente significante (HAYASHI, 2004). 
Em um dos cães foi notada a presença de deiscência de retalho. É sabido que a exposição das membranas leva a piores resultados de regeneração do que quando estas ficam submersas no tecido conjuntivo. A exposição da membrana leva à sua contaminação e ela acaba agindo como corpo estranho na área de reparação, levando a um aumento de infiltrado inflamatório, o que prejudica a reparação. (FRANDSEN et al., 1994; SANDER et al., 1994). Neste cão houve uma maior migração apical do epitélio juncional no lado teste que nos outros cães.

É necessário lembrar que este estudo utilizou animais, sendo um equívoco esperar que estes resultados possam ser extrapolados para seres humanos, além do que, neste estudo, não foram tratados defeitos decorrentes de doença periodontal, como no trabalho de Bogle et al. (1997), e sim defeitos agudos criados artificialmente. Também, deve-se ter em mente que a manutenção do retalho em posição coronária é difícil, pois traumas mecânicos, ou até mesmo falhas na sutura podem levar à retração deste. A anatomia das coroas dentais dos pré-molares dos cães também permite uma melhor adaptação do retalho ao leito se comparado às coroas humanas. Embora a histometria não tenha sido capaz de demonstrar diferenças significantes quando se empregou RTG no trabalho predecessor a este, trabalhos simultâneos, realizados com metodologia semelhante, pois, no lado teste não foi utilizada a RTG, também falharam em demonstrar resultados com diferenças estatisticamente significantes. Em ambos os trabalhos não foram utilizadas as membranas mas apenas o tecido ósseo neoformado (YORIOKA, 2004) ou o tecido ósseo neoformado enriquecido com fatores de crescimento (SOARES et al., 2005).

Embora não se saiba com exatidão o papel das Proteínas da Matriz Extracelular (PMEs) no processo de reparação periodontal (GANSS; KIM; SODEK, 1999) alguns estudos demonstraram algumas propriedades interessantes. Assim, 
utilizando os mesmos espécimes do estudo predecessor (HAYASHI, 2004), foram realizadas as avaliações imuno-histoquímicas para tentar elucidar se os eventos ocorridos no período de 45 dias, relacionados às PMEs, poderiam ajudar a explicar os resultados do estudo anterior e ainda tentar adicionar mais informações sobre o comportamento das PMEs na reparação.

A imuno-histoquímica revelou uma paridade entre os grupos teste e controle na qualidade de marcação dentro dos grupos ONC e grupo BSP nas estruturas analisadas. Para a OPN a marcação nos tecidos moles ocorreu de maneira que não permitiu comparação entre os grupos testes e controle, uma vez que nos lados linguais aos defeitos, os tecidos moles não demonstraram similaridade de marcação. Isto foi contraditório porque, como os lados linguais não foram instrumentados, esta similaridade era esperada. Nos tecidos duros para OPN houve uma similaridade nos lados linguais.

Dentre os marcadores, a ONC foi a que apresentou marcação mais específica nos neoformados osso e cemento. Talvez este fato denote a importância de seu papel no processo de neoformação destes tecidos. Entre as propriedades da ONC está o seu papel no controle da diferenciação e proliferação celular sendo a contraadesão um dos mecanismos deste controle (YAN; SAGE, 1999). Esta propriedade talvez tenha um papel diminuído no osso maduro, uma vez que as exigências proliferativas e de diferenciação sejam menores, o que explicaria não marcação do cemento e a pouca ou a não marcação da matriz óssea . Outra característica interessante é o fato de que o colágeno tipo I, ao se ligar a ONC, consegue se ligar à apatita e ao cálcio (TERMINE et al., 1981), isto pode indicar que a demanda por minerais seja maior nos tecidos em reparação. 
Os estudos de Amar et al. $(1995,1997)$ utilizaram a marcação pela ONC em defeitos periodontais tratados pela RTG. Entretanto, os estudos foram conduzidos em humanos e macacos respectivamente, o que dificulta uma comparação com o presente estudo. Em contraste com nosso estudo, Amar e colaboradores encontraram marcação em áreas de tecido conjuntivo denso que eles supuseram ser uma matriz prévia à mineralização e não encontraram a ONC no novo osso. $O$ tempo de estudo, 6 semanas, se assemelha ao do presente estudo, porém, em cães talvez este período deva representar uma reparação mais avançada ou diferente, uma vez que, em nosso trabalho, o tecido conjuntivo não apresentou marcação evidente e o novo osso sim.

A marcação nos tecidos duros pela BSP foi mais forte no cemento e osso novos, tanto para a parte celular quanto para as matrizes, sendo que, para a matriz do cemento, no tecido maduro, a tendência foi para a marcação negativa e no novo cemento essa marcação foi forte. Esta maior concentração de BSP pode ressaltar a importância da BSP nos eventos de reparação periodontal. Também, a BSP parece ser mais abundante quando na presença do mineral extrafibrilar (GANSS; KIM; SODEK, 1999) que é abundante no osso imaturo. Semelhante a Ivanovski et al. (2000) a BSP também marcou moderadamente a matriz extracelular do tecido conjuntivo do defeito em reparação e, fortemente, o cemento, a matriz extracelular do novo osso e as células de linhagem óssea. Christgau et al. (2007) também encontraram, nas interfaces cemento-dentina e superfície do novo cemento, linhas mais definidas marcadas pela BSP. Estas linhas mais definidas e com marcação mais forte podem indicar maior concentração da BSP nestas áreas, levando a entender que tenha um papel importante na deposição inicial de cemento sobre a dentina, bem como na superfície do novo cemento. 
A marcação para a OPN, como dito anteriormente, apresentou um padrão atípico quando analisados os tecido conjuntivo e ligamento periodontal linguais ao defeito. Estes não apresentaram uma resposta semelhante às reações imunohistoquímicas, quando a semelhança era esperada. Como isto não ocorreu, não serão discutidos os aspectos imuno-histoquímicos encontrados nestas áreas e no tecido conjuntivo presente na área em reparação. Na área do cemento e osso, novos ou pré-existentes, o padrão de marcação foi semelhante. A OPN teve uma marcação semelhante quando se comparou tecidos duros pré-existentes e novos mas, linhas mais coradas foram mais perceptíveis entre a dentina e o novo cemento, novo cemento e o tecido conjuntivo e entre este e o novo osso. Este aspecto foi semelhante ao que foi observado nos estudos de Christgau et al. (2007), Ivanovski et al. (2000), Kawaguchi et al. (2001) e Sculean et al. (2002), corroborando com a idéia de a OPN desenvolva algum papel na deposição inicial de novo cemento e de novo osso.

Linhas de reversão foram marcadas pela BSP e ONC e, juntamente com o fato de ter sido encontrado uma linha de marcação mais nítida entre a dentina e o novo cemento para BSP, ONC e OPN, pode-se supor a importância destas na modificação da superfície radicular/óssea para a futura aderência celular ou deposição inicial da matriz de cemento ou osso. Um fator interessante observado foi que, semelhante aos achados de Christgau et al. (2007), havia áreas de espessura muito delgada sobre a dentina. Estas foram marcadas por imuno-histoquímica para os diferentes marcadores estudados. Christgau et al. (2007) indicaram estas estruturas como um cementóide, que veio a constituir um cemento de maior espessura após três meses de reparação. Embora nosso estudo tenha mais de seis semanas de reparação, e não tenha sido realizado um acompanhamento entre 
diferentes momentos de reparação, isto pode indicar a possibilidade de formação de um cemento mais característico em estágios mais avançados de reparação do que os 45 dias estudados. Também, este tecido de espessura delgada, aparentemente foi mais freqüente sobre a dentina do grupo teste, o que pode representar uma menor velocidade na reparação e maturação tecidual em relação ao grupo controle. É importante lembrar que Christgau et al. (2007) notaram que, a partir de quatro semanas, as fibras colágenas começaram a ser inseridas no cemento e o ligamento periodontal só foi completado aos três meses. Entretanto, em oito semanas, a maior parte do cemento que iria recobrir a superfície dentinária já estava presente. Em nosso estudo não temos o tempo de reparação de três meses. Assim, é difícil saber o tempo total necessário para a formação do ligamento periodontal e, se no período de oito semanas teria sido aumentada a faixa de novo cemento, principalmente nas áreas marginais, onde havia fibras colágenas paralelas à superfície da dentina, com uma camada muito fina de material imunorreativo entre a dentina e o tecido conjuntivo.

Tanto para a BSP quanto para a OPN, no presente estudo, foi observada uma marcação maior nas superfícies dos novos cemento e osso, como Christgau et al. (2007) também descreveram.

A maior presença das PME(s) nas fases imaturas dos tecidos mineralizados pode estar ligada à necessidade de maior quantidade destas no processo de reparação, entretanto, é importante salientar que não encontrar ou encontrá-las em menor quantidade nos tecidos mineralizados maduros por meio de reações imunohistoquímicas possa ocorrer devido aos antígenos poderem estar mais "protegidos" dos anticorpos pelo maior grau de mineralização nos tecidos maduros que nos imaturos. Este fato foi salientado por Christigau et al. (2007). 
Sobre a marcação de tecidos não mineralizados, como o ligamento periodontal, tecido conjuntivo e epitélio, Sculean et al. (2002) enfatizaram que isto pode ocorrer devido à presença das $\mathrm{PME}(\mathrm{s})$ também em tecidos não mineralizados, ou ainda, que isto pode ocorrer devido à utilização de anticorpos policlonais, não específicos da espécie estudada. Isto talvez possa explicar a marcação forte das membranas por todos os agentes imuno-histoquímicos estudados, uma vez que as membranas podem estar impregnadas por proteínas diversas, referentes ao meio em reparação. Também, os constituintes das membranas podem ser reativos aos corantes utilizados no estudo.

As reações imuno-histoquímicas revelaram uma marcação equivalente entre os marcadores utilizados quando comparados os tecidos em reparação. Assim, aparentemente, a utilização da RTG associada ao retalho deslocado coronariamente não provocou diferenças no padrão marcação das PME(s) estudadas, havendo uma reparação semelhante entre os grupos. Ivanovski et al. (2000) ressaltaram que entender a reparação através das proteínas envolvidas é algo complicado, uma vez que a reparação envolve diferentes e inúmeras interações moleculares e celulares. Logicamente, mais estudos são necessários para que se possa entender, mais profundamente, o papel das $\mathrm{PME}(\mathrm{s})$ na reparação periodontal. 


\section{CONCLUSÃO}

As reações imuno-histoquímicas para a osteonectina, osteopontina e sialoproteína óssea revelaram um padrão de marcação semelhante nos tecidos duros em reparação, quando comparamos os grupos teste e controle, levando a crer que o uso da RTG associada ao enxerto de tecido reparativo de alvéolos não interferiu no estágio reparativo. Os grupos estavam em um estágio semelhante de reparação. Outros estudos são necessários para se entender o papel das $\operatorname{PME(s)~na~}$ reparação periodontal e, também, seria interessante o desenvolvimento de estudos que utilizassem anticorpos específicos para cães, para evitar marcações inesperadas. 


\section{REFERÊNCIAS ${ }^{1}$}

Amar S, Petrungaro P, Amar A, Van Dyke TE.Immunolocalization of bone matrix macromolecules in human tissues regenerated from periodontal defects treated with expanded polytetrafluoroethylene membranes. Arch Oral Biol 1995 Jul;40(7):653-61.

Amar S, Chung KM, Nam SH, Karatzas S, Myokai F, Van Dyke TE. Markers of bone and cementum formation accumulate in tissues regenerated in periodontal defects treated with expanded polytetrafluoroethylene membranes.J Periodontal Res 1997 Jan;32(1 Pt 2):148-58.

Amler $\mathrm{MH}$.The effectiveness of regenerating versus mature marrow in physiologic autogenous transplants. J Periodontol 1984 May;55(5):268-72.

Andersson B, Bratthall G, Kullendorff B, Grondahl K, Rohlin M, Attstrom R.Treatment of furcation defects. Guided tissue regeneration versus coronally positioned flap in mandibular molars; a pilot study. J Clin Periodontol 1994 Mar;21(3):211-6.

Bogle G, Garrett S, Stoller NH, Swanbom DD, Fulfs JC, Rodgers PW, et al. Periodontal regeneration in naturally occurring Class II furcation defects in beagle dogs after guided tissue regeneration with bioabsorbable barriers. J Periodontol 1997 Jun;68(6):536-44.

Brunsvold MA, Mellonig JT. Bone grafts and periodontal regeneration. Periodontol 20001993 Feb;1:80-91.

Caffesse RG, Smith BA, Castelli WA, Nasjleti CE. New attachment achieved by guided tissue regeneration in beagle dogs. J Periodontol 1988 Sep;59(9):589-94.

Caffesse RG, Nasjleti CE, Plotzke AE, Anderson GB, Morrison EC. Guided tissue regeneration and bone grafts in the treatment of furcation defects. J Periodontol 1993 Nov;64(11 Suppl):1145-53.

Caffesse RG, Nasjleti CE, Morrison EC, Sanchez R. Guided tissue regeneration: comparison of bioabsorbable and non-bioabsorbable membranes. Histologic and histometric study in dogs. J Periodontol 1994 Jun;65(6):583-91. 
Caton J, Nyman S, Zander H. Histometric evaluation of periodontal surgery. II. Connective tissue attachment levels after four regenerative procedures. J Clin Periodontol 1980 Jun;7(3):224-31.

Christgau M, Caffesse RG, Schmalz G, D'Souza RN. Extracellular matrix expression and periodontal wound-healing dynamics following guided tissue regeneration therapy in canine furcation defects. J Clin Periodontol 2007 Aug;34(8):691-708. Epub 2007 Jun 21.

Clafin RS. Healing of diturbed and undisturbed extraction wounds. J Am Dent Assoc 1936 Jun;23(6):945-59.

Cordioli MAG. Análise histológica e índice de proliferação celular do tecido reparativo de alvéolos dentários de cães, tratados ou não com os fatores de crescimento PDGF-BB e IGF-I, associados [Tese de Doutorado]. São Paulo: Faculdade de Odontologia da USP; 2002.

Cordioli MAG. Reparação óssea alveolar pós-exodontia em cães, com e sem o uso de membrana de PTFE-E : análise histológica [Dissertação de Mestrado]. São Paulo: Faculdade de Odontologia da USP; 1999.

Cowles EA, DeRome ME, Pastizzo G, Brailey LL, Gronowicz GA. Mineralization and the expression of matrix proteins during in vivo bone development. Calcif Tissue Int 1998 Jan;62(1):74-82.

Crigger M, Bogle G, Nilveus R, Egelberg J, Selvig KA. The effect of topical citric acid application on the healing of experimental furcation defects in dogs. J Periodontal Res 1978 Nov;13(6):538-49.

De Vuono MS. Análise histológica e do índice de proliferação celular da reparação de alvéolos dentários de cães tratados com o fator de crescimento IGF-I [Dissertação de Mestrado]. São Paulo: Faculdade de Odontologia da USP; 2002.

Ferraro AQ. Análise comparativa, histológica e imuno-histoquímica, da reparação de alvéolos tratados ou não com o fator de crescimento PDGF-BB [Dissertação de Mestrado]. São Paulo: Faculdade de Odontologia da USP; 2002. 
Fisher LW, Hawkins GR, Tuross N, Termine JD. Purificatin and Partial characterization of small proteoglycans I and II, bone sialoproteins I and II, and osteonectin from the mineral comparment of developing human bone. J Biol Chem 1987;262(20):9702-852

Frandsen EV, Sander L, Arnbjerg D, Theilade E. Effect of local metronidazole application on periodontal healing following guided tissue regeneration. Microbiological findings. J Periodontol 1994 Oct;65(10):921-8.

Ganss B, Kim RH, Sodek J. Bone sialoprotein. Crit Rev Oral Biol Med 1999;10(1):7998.

Gantes B, Martin M, Garrett S, Egelberg J. Treatment of periodontal furcation defects. (II). Bone regeneration in mandibular class II defects. J Clin Periodontol 1988 Apr;15(4):232-9.

Garrett S. Early wound healing stability and its importance in periodontal regeneration. In: Polson A. Periodontal regeneration - current status and directions. St. Louis: Quintessence; 1994. cap. 3, p. 41-51.

Garrett S, Bogle G. Periodontal regeneration: a review of flap management. Periodontol 20001993 Feb;1(1):100-8

Goldman, HM, Cohen, DW. The infrabony pocket: classification and treatment. J Periodontol 1958 Oct;29(4):272-91.

Gottlow J, Nyman S, Karring T, Lindhe J. New attachment formation as the result of controlled tissue regeneration. J Clin Periodontol 1984 Sep;11(8):494-503.

Hayashi F. Retalho deslocado coronariamente, associado ou não à regeneração tecidual guiada e enxerto de coágulo pós-extração, em defeitos de furca grau II, em cães [Dissertação de Mestrado]. São Paulo: Faculdade de Odontologia da USP; 2004.

Ivanovski S, Li H, Daley T, Bartold PM. An immunohistochemical study of matrix molecules associated with barrier membrane-mediated periodontal wound healing. $J$ Periodontal Res 2000 Jun;35(3):115-26.

Karring T, Lindhe J, Cortellini P. Tratamento periodontal regenerativo. In: Lindhe J, Karring T, Lang NP. Tratado de periodontia clínica e implantologia oral. $3^{a}$. ed. Trad. 
de Edson J. L. Moreira et al. Rio de Janeiro: Guanabara Koogan; 1999. cap. 20, p. 428-62.

Kawaguchi $\mathrm{H}$, Ogawa $\mathrm{T}$, Kurihara $\mathrm{H}$, Nanci A. Immunodetection of noncollagenous matrix proteins during periodontal tissue regeneration. J Periodontal Res 2001 Aug;36(4):205-13.

Klinge B, Nilveus R, Egelberg J. Effect of crown-attached sutures on healing of experimental furcation defects in dogs. J Clin Periodontol 1985 May;12(5):369-73.

Lao M, Marino V, Bartold PM. Immunohistochemical study of bone sialoprotein and osteopontin in healthy and diseased root surfaces. J Periodontol 2006 Oct;77(10):1665-73.

Lekovic V, Kenney EB, Carranza FA Jr, Danilovic V. Treatment of class II furcation defects using porous hydroxylapatite in conjunction with a polytetrafluoroethylene membrane. J Periodontol 1990 Sep;61(9):575-8.

Listgarten MA, Rosenberg MM. Histological study of repair following new attachment procedures in human periodontal lesions. J Periodontol 1979 Jul;50(7):333-44.

Magnusson I, Batich C, Collins BR. New attachment formation following controlled tissue regeneration using biodegradable membranes. J Periodontol 1988 Jan;59(1):1-6.

Nanci A, Somerman M. The periodontium. In: Nanci A. Ten Cate's oral histology: development, structure, and function. St Louis: Harcourt Sciences. 2003. cap. 9, p. 239-67.

Nyman S, Lindhe J, Karring T, Rylander H. New attachment following surgical treatment of human periodontal disease. J Clin Periodontol 1982 Jul;9(4):290-6.

Passanezi E, Janson WA, Nahas D, Campos Junior A. Newly forming bone autografts to treat periodontal infrabony pockets: clinical and histological events. Int J Periodontics Restorative Dent 1989;9(2):140-53.

Prichard J. Regeneration of bone following periodontal therapy; report of cases. J Oral Surg (Chic) 1957 Mar;10(3):247-52. 
Roach HI. Why does bone matrix contain non-collagenous proteins? The possible roles of osteocalcin, osteonectin, osteopontin and bone sialoprotein in bone mineralisation and resorption. Cell Biol Int 1994 Jun;18(6):617-28.

Sander L, Frandsen EV, Arnbjerg D, Warrer K, Karring T. Effect of local metronidazole application on periodontal healing following guided tissue regeneration. Clinical findings. J Periodontol 1994 Oct;65(10):914-20.

Sculean A, Junker R, Donos N, Berakdar M, Brecx M, Dünker N.

Immunohistochemical evaluation of matrix molecules associated with wound healing following regenerative periodontal treatment in monkeys. Clin Oral Investig. 2002 Sep;6(3):175-82 Epub 2002 Jul 12.

Selvig KA. Discussion: Animal Models in Reconstructive Therapy. J Periodontol 1994 Dec; 65(12):1169-72.

Soares FP, Hayashi F, Yorioka CW, Pannuti CM, Gioso MA, de Lima LA, et al. Repair of Class II furcation defects after a reparative tissue graft obtained from extraction sockets treated with growth factors: a histologic and histometric study in dogs. J Periodontol 2005 Oct;76(10):1681-9.

Sodek J, Ganss B, McKee MD. Osteopontin. Crit Rev Oral Biol Med 2000;11(3):279303.

Termine JD, Kleinman HK, Whitson SW, Conn KM, McGarvey ML, Martin GR. Osteonectin, a bone-specific protein linking mineral to collagen. Cell. 1981 Oct;26(1 Pt 1):99-105.

Tung PS, Domenicucci C, Wasi S, Sodek J. Specific immunohistochemical localization of osteonectin and collagen types I and III in fetal and adult porcine dental tissues. J Histochem Cytochem 1985 Jun;33(6):531-40.

Wikesjö UM, Nilveus RE, Selvig KA. Significance of Early Healing Events on Periodontal Repair: A Review. J Periodontol 1992 Mar; 63(3):158-65. 
Wikesjö UM, Selvig KA. Periodontal wound healing and regeneration. Periodontol 20001999 Feb;19:21-39.

Yan Q, Sage EH. SPARC, a matricellular glycoprotein with important biological functions. J Histochem Cytochem 1999 Dec;47(12):1495-506.

Yorioka, CW. Tratamento de defeitos de furca classe II com o uso de enxerto de coágulo e retalho deslocado coronariamente: estudo em cães [Dissertação de Mestrado]. São Paulo: Faculdade de Odontologia da USP; 2004. 
ANEXO

\title{
ANEXO A - Parecer do comitê de ética
}

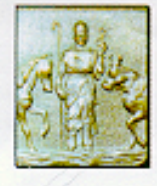

\author{
UNIVERSIDADE DE SÃO PAULO \\ Faculdade de Medicina Veterinária e Zootecnia \\ Cidade Universitária “Armando de Salles Oliveira” \\ Comissão Bioética
}

\section{CERTIFICADO}

Certificamos que o Projeto intitulado "Reparação periodontal de defeitos de furca classe II com o uso de enxerto de tecido ósseo neoformado em alveólos em reparação (Tratados com fatores de crescimento e/ou membranas) estudo em cães", Protocolo n ${ }^{\circ}$ 155/2002, sob a responsabilidade do Prof.Dr. Marco Antonio Gioso, está de acordo com os princípios éticos de experimentação animal da Comissão de Bioética da Faculdade de Medicina Veterinária e Zootecnia da Universidade de São Paulo sendo aprovado "ad referendun".

(We certify that the Research "Preiodontal healing in furcation defect class II with new bone graft in alveolous (treated with growth factors or membranes) in dogs" protocol number 155/2002, under the responsability of Prof.Dr. Marco Antonio Gioso, agree with Ethical Principles in Animal Research adopted by Bioethic Commision of the Faculty of Veterinary Medicine and Zootechny of University of São Paulo and was approved "ad referendun" meeting.)

São Paulo, 21 de junho de 2002

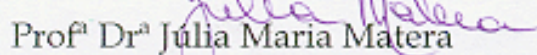

Presidente da Comissão de Bioética

FMVZ/USP 